\title{
ECONOMÍA POLÍTICA Y MANUFACTURAS: UNA PERSPECTIVA REGIONAL
}

\section{Political economy and manufactures: A regional perspective}

\author{
Joaquín OCAMPO SUÁREZ-VALDÉS \\ Universidad de Oviedo \\ jocampo@uniovi.es \\ Patricia SUÁREZ CANO \\ Universidad de Oviedo \\ suarezcpatricia@uniovi.es
}

Fecha de recepción: 2/07/2018

Fecha de aceptación definitiva: 1/07/2019

RESUMEN: El estudio del sector manufacturero español del siglo XVIII goza de amplia cobertura historiográfica: a los análisis regionales, sectoriales y empresariales, se han sumado los referidos al «legado industrial» del Antiguo Régimen. Por lo mismo, en este artículo se ha optado por una nueva aproximación: valorar la eficacia de las tesis industrialistas formuladas desde la economía política, con su traslación a las políticas económicas, y analizar el alcance de las medidas de fomento del sector auspiciadas por instituciones regionales o forales -sociedades económicas, academias de agricultura y artes, consulados, juntas de comercio...-.

Pese a la proliferación de iniciativas empresariales o a la disponibilidad de capitales, serán contados los sectores -algodón, harinería, papel...- que aporten un modelo técnico y organizativo viable. Y ello por cuanto a las restricciones institucionales se añadirían otras limitaciones de peor arreglo: baja productividad agraria, escaso desarrollo urbano o débil integración del mercado, entre otras.

Palabras clave: economía política; empresa; manufacturas; regiones. 
ABSTRACT: XVIIIth Spanish industrial manufacturing has been duly covered by historiography: besides regional, sectorial and corporate analyses we can also count on studies centered upon the "industrial legacy» of the Ancien Régime. That is the very reason why this article has been tackled from a new perspective, based not only on assessing the degree of efficiency of theses formulated from the angle of political economics but on analysing the depth reached by regional initiatives for development springing from economic societies, farming and art academias, consulates, trading corporations, among others.

Despite the high number of corporate initiatives and the availability of capital, there were very few sectors (cotton, flour, paper manufacturing) showing a truly viable technical and organizational model. Institutional restrictions and social resistance added to other limitations with no easy solution: low productivity rate, poor urban development or weak market integration, among others.

Key words: Political economics; corporation; manufacture; regions.

Oh! industria, madre fecundísima de todos aquellos bienes que puede desear la sociedad (Dámaso Generés, 1793) ${ }^{1}$.

\section{INTRODUCCIÓN}

La historiografía del sector manufacturero en el siglo XVIII cuenta con una dilatada tradición que a los análisis regionales, sectoriales o empresariales ha sumado visiones de síntesis y balances referidos al «legado industrial» del Antiguo Régimen ${ }^{2}$. El panorama se ha visto enriquecido en los últimos años por la renovación de los estudios modernistas. La incorporación de nuevos indicadores económicos -salarios, productividad del trabajo agrícola, urbanización, consumo, funcionamiento de los mercados- ha permitido mejorar el conocimiento de la trayectoria del sector tanto en términos absolutos como comparados. En este último sentido, Enrique Llopis ha referido cómo el mediocre resultado de la economía española en aquel siglo -baja densidad urbana, caída de salarios reales, retroceso de la propiedad campesina y de los niveles de demanda...- avalaría el deterioro

1. La cita en DÁmaso GENERÉs, M. Reflexiones políticas y económicas sobre legislación, agricultura, artes, fábricas y comercio de Reyno de Aragón (1793). Ed. de E. Lluch y A. Sánchez Hormigo. Zaragoza: Fundación Fernando el Católico, 1996, p. 47.

2. Vid., entre otras: Benaul, J. M. y SÁnchez, A. "El legado industrial del Antiguo Régimen". En Llopis, E. (ed.). El legado económico del Antiguo Régimen. Barcelona: Crítica, 2004, pp. 187-228; OCAMPo SuÁrez-VAldés, J. "Empresas y empresarios en el siglo XVIII». En OCAMPO, J. (ed.). Empresas y empresarios en el norte de España (siglo XVIII). Gijón: Trea, 2012, pp. 9-38. 
fabril español y el bajo nivel de industrialización ${ }^{3}$. Por su parte, Marcos Martín habla de "recuperación incompleta": aun cuando se diese una respuesta positiva de la producción manufacturera a la demanda doméstica y colonial, se trataría de una respuesta extensiva. A la hora de ofrecer explicaciones, la causalidad apunta a factores estructurales: por el lado de la demanda, a la dependencia del ciclo industrial respecto al agrario y demográfico; por el de la oferta, a los relacionados con los costes de producción, con la deserción de capital mercantil o con la incapacidad de abastecer competitivamente los diferentes mercados ${ }^{4}$. Este trabajo adopta una doble perspectiva: la aportada por la economía política -con su traslación a las políticas industriales del reformismo borbónico- y la procedente de instituciones regionales -sociedades económicas, academias, consulados, juntas de comercio- que, con diversa suerte, aspiraron a representar los intereses industriales.

\section{ECONOMÍA POlítiCA DE LA ILUSTRACiÓN: EL DisCURSO INDUSTRIALISTA}

Los productos de la industria de una nación forman el barómetro más seguro por donde se debe regular la progresión o decadencia del Estado, de su riqueza (Campomanes, 1774).

El debate sobre qué sector productivo fomentar formaba parte de la tradición arbitrista ${ }^{6}$. Desde el Memorial (1558) de Luis Ortiz, la crítica a la escasa competitividad de las manufacturas españolas se generaliza: los extranjeros, dirá, "nos llevan el dinero con su industria». Frente a las tesis agraristas (Arrieta, Lope de Deza o Caxa de Leruela), el "grupo de Toledo» (Ceballos, Moncada, Olivares) esgrimirá la superioridad de la industria por su mayor valor añadido, por su contribución a la generación de empleo y por su función equilibradora de la balanza comercial.

En los repertorios de bibliografía económica del XVIII, son contadas las monografías que incorporan el término industria a su título: es el caso de algunos informes (Uztáriz) y memorias (Capmany, Larruga, Polo y Catalina), y el de las obras de Ulloa -Restablecimiento de las fábricas, 1740- y Campomanes -Discurso sobre el fomento de la industria popular, 1774-. La explicación posiblemente resida en que el sector fabril se percibía como subordinado al agrario y comercial.

3. Cfr. Llopis, E. "España, la "revolución de los modernistas" y el legado del Antiguo Régimen". En Llopis, E. (ed.). Op. cit., 2004, pp. 11-76.

4. Marcos Martín, A. España en los siglos XVI, XVII y XVIII. Economía y sociedad. Barcelona: Crítica/Caja Duero, 2000, pp. 244-256.

5. Cit. en Rodríguez Campomanes, P. Discurso sobre el fomento de la industria popular. Madrid: Imp. de A. Sancha, 1774, p. 181.

6. Vid. PERDiCes DE Blas, L. «La restauración de la riqueza de España por la industria. Reflexiones sobre el industrialismo de los arbitristas del siglo XVII». En BEL, G. y EsTRUCH, A. (eds.). Industrialización en España: entusiasmos, desencantos y rechazos. Madrid: Cívitas, 1997, pp. 31-61. 
Era así porque, dentro de la matriz de las economías de base orgánica, se hallaba generalizada la opinión, compartida por Adam Smith, de la superioridad de las actividades agrarias: las manufacturas de Sheffield, Halifax o Leeds, dirá, son «hijas de los adelantos de la agricultura ${ }^{7}$. Pese a todo, la economía política desarrollará un discurso industrialista propio.

1.1. Las relaciones agricultura/industria: ¿especialización agraria o desarrollo sectorial equilibrado?

En 1774, Campomanes se refería a la "benéfica constitución económica" de Galicia como "más sólida y duradera» que la catalana por cuanto aquella, "de tiempo inmemorial, ha unido la labranza con la industria ${ }^{8}$. Con similar criterio Capmany consideraba la concentración fabril en torno a Barcelona como el anticipo de la quiebra económica del orden tradicional. En el extremo opuesto se situaban quienes, como Romá i Rosell o Arriquibar, consideraban que el desarrollo industrial no solo no entorpecía al agrario, sino que era condición previa para su despegue? Entre ambas posiciones y en línea con Boisguilbert o Cantillon, tendió a imponerse una visión agregada e intersectorial de la economía. Así, en 1762, Ward, comparando las economías de Polonia o Ucrania con las de Francia e Inglaterra, concluía que «donde florecen las fábricas, florece a paso igual la agricultura». Desde Aragón, Generés veía en Cataluña el mejor ejemplo del eslabonamiento agricultura/industria pues allí el desarrollo fabril «obliga a las enhiestas y escarpadas montañas a que den frutos». Para Normante, la industria catalana era «eficaz causa de que no haya en el Principado un palmo de tierra que no esté en cultivo» ${ }^{10}$.

7. Cfr. BERG, M. «Political economy and the principles of manufacture (1700-1800)». En HUDSON, P. et al. (eds.). Manufactures, town and country before the factory. Cambridge: CUP, 1983, pp. 33-61.

8. Las citas en OCAMPO, J. "Industrialismo antes de la revolución industrial: la visión de los ilustrados». Cuadernos de Estudios del Siglo XVIII, 2002, 12-13, pp. 93-115.

9. Sostenía Romá que, frente a "algunos modernos excesivamente idólatras de la agricultura", los brazos que pudieran detraer las fábricas quedarían «superabundantemente compensados con la utilidad de las artes». Para Arriquibar, "si la agricultura tiene sus límites, el campo de la industria es tan vasto como interminable». Jovellanos, ya en la senda de A. Smith, refinaba tales argumentos: "La agricultura solo puede aumentar la población de un país hasta un cierto punto, porque el terreno cultivable y aún la perfección del cultivo tienen sus límites señalados por la naturaleza». Las citas en ROMÁ I RoselL, F. Las señales de la felicidad de España y medios de hacerlas eficaces (1768). Ed. E. Lluch. Barcelona, 1989, p. 107; ARriquibar, N. Recreación política (1779). Ed. de J. Astigarraga y J. M. Barrenechea. Vitoria, 1987, pp. 303 y 314; Jovellanos, G. M. de. "Informe sobre el libre ejercicio de las artes» (1785). En Obras completas. X. Escritos económicos. Ed. de V. Llombart y J. Ocampo. Oviedo: Instituto Feijoo de Estudios del Siglo XVIII, KRK, 2008, pp. 509-541.

10. Las referencias en WARD, B. Proyecto económico en que se proponen varias providencias dirigidas a promover los intereses de España con los medios y fondos necesarios para su planificación (1779). Ed. de J. L. Castellano. Madrid: Instituto de Estudios Fiscales, 1982, p. 182; DÁmaso GENERÉs, M. Reflexiones políticas y económicas..., op. cit., p. 158; Normante y CarCavila, C. Proposiciones de economía civil y de comercio (1785). Ed. A. Peiró Arroyo. Zaragoza, 1984, p. 46. 
Los debates doctrinales se irán atenuando hacia finales de siglo. Aun cuando en 1797 Ramón Campos, al reproducir en La Económica el esquema analítico de A. Smith, mantenía la prioridad de la agricultura en el «orden natural» del progreso, Jovellanos, por las mismas fechas, daba por zanjado el tema:

De estas reflexiones resulta una verdad muy importante para la economía política, y es que las fuentes de riqueza pública no solo están enlazadas, sino que también dependen unas de otras. Por lo mismo, parece inútil indagar cuál de ellas sea la primera $^{11}$.

Si en 1804 el Discurso sobre las fábricas e industria de España, de Juan Polo y Catalina, parecía despejar el camino hacia posiciones netamente industrialistas ${ }^{12}$, las tesis agraristas volvían a imponerse en las Cortes de Cádiz: solo 11 de las 6.255 páginas de los diarios de sesiones y solo 6 de los 316 decretos dictados se ocuparán parcialmente de la industria. García Sanz ha explicado la paradoja de que una burguesía teóricamente revolucionaria optase por el capitalismo agrario frente al industrial. En una de la sesiones, Calatrava llegará a exclamar: «¡Ojalá que en España hubiese toda la agricultura de que es capaz, y entonces me daría bien poco cuidado el que tuviésemos fábricas!» ${ }^{13}$.

\subsection{Gestión, titularidad y modelo fabril}

En la primera mitad del siglo y siguiendo la estela de Uztáriz, Ulloa, Argumosa y Zabala, ya habían asumido el fracaso de las manufacturas reales tanto en términos macroeconómicos -sustitución de importaciones, adopción de tecnologías innovadoras, corrección de desequilibrios territoriales-, como empresariales -eficiencia, gestión, resultados contables...-. En la Theórica (1724), Uztáriz sostenía que el fomento privado de las manufacturas resultaba "más seguro y eficaz que la administración por cuenta del soberano» ${ }^{14}$.

Desde 1750, las críticas a la industrialización de Estado se nutrirán de dos nuevos argumentos. El primero -asociado a la recepción del «mercantilismo liberal»

11. Para las citas: CERVERA FERRI, P. El pensamiento económico de la Ilustración valenciana. Valencia: Generalitat de Valencia, 2003, pp. 141-144; Jovellanos, G. M. de. «Introducción a un discurso sobre la Economía civil»(1796). En Obras completas. X. Escritos económicos, cit., p. 890.

12. Vid. SÁnchez Hormigo, A. (ed.). Juan Polo y Catalina: Informe sobre las fábricas e industria de España (1804) y otros escritos. Zaragoza: Prensas Universitarias, 2005, pp. 38-46.

13. Cfr. OcAmpo, J. «Economía, Ilustración y Liberalismo: las Cortes de Cádiz». Brocar, 2012, 36, pp. 139-161.

14. Cfr. Theórica y práctica de comercio y de marina (1724). Ed. de G. Franco. Madrid: I. E. Fiscales, 1968, cap. XCVIII, p. 333. Sobre la cuestión expuesta: Helguera, J. "Las Reales Fábricas». En Comín, F. y Martín Aceña, P. (dir.). Historia de la empresa pública en España. Madrid: Espasa-Calpe, 1991, pp. 55-88, pp. 51-88, y TEDDE, P. «La empresa pública en el mercantilismo español del siglo XVIII». Ibid., pp. 25-50. 
inglés a través de las traducciones francesas del grupo de Gournay- postulaba la defensa del "orden natural» e iba unido al énfasis en la eficiencia asignativa del mercado. El segundo, más empírico, tenía que ver con el mejor conocimiento de la realidad fabril europea. En 1759, Ward era comisionado por Fernando VI para viajar por Europa "cotejando los adelantamientos de otras naciones en perfeccionar la industria». A la vuelta de su encargo daba a conocer el éxito de los distritos manufactureros rurales ingleses y de la producción descentralizada de los "fabricantes sin fábrica» (Torras). En su Proyecto económico -redactado en 1762 y editado en 1779-, escribiría:

El método que seguimos en alguna parte de España de tener edificios grandes aparte para una industria, es contrario a la buena economía y al estilo de Inglaterra [...] En Bretaña e Irlanda, he visto una práctica que contribuye a abaratar el trabajo: un gran número de los que tejen géneros de lino y lana de mediana calidad, son labradores [...]. Las fábricas de las ciudades, regularmente, no tienen allí sino los almacenes, tintes, prensas y talleres para dar la última mano, pero el hilar, tejer y gran parte de las demás maniobras, se hacen en las aldeas circunvecinas, donde están más baratos los combustibles, el jornal y las materias primas [...] y en las que no hay leyes ni privilegios de comunidades ${ }^{15}$.

Vidal y Cabasés se hacía igualmente eco de cómo en Inglaterra «comerciantes y caballeros opulentos» formaban compañías por acciones para "mantener y fomentar fábricas» que incorporaban «bombas de fuego»:

Los mismos comerciantes las mantienen y fomentan haciendo trabajar a los mejores operarios sin salir de sus viviendas. La Gran Bretaña ha procurado el adelantamiento de sus fábricas estableciéndolas en las aldeas. Ha hallado asimismo la gran economía de hacer por medio de ingenios y máquinas muchísimas maniobras que hacían antes los hombres ${ }^{16}$.

La presencia del capital mercantil en las redes comerciales y en el control del proceso productivo era un hecho conocido y admitido. La defensa por Campomanes de la «industria rústica» y popular (Kaufsystem) en el ámbito rural no excluía la del Verlagssystem:

Tan lejos está de que sea perjudicial a los artesanos fabricar por cuenta de comerciantes que, antes, es este el único medio de mantener pujantes las manufacturas y que el artista tenga alguien que le anticipe caudales para acopiar materiales y

15. Cfr. WARD, op. cit., 1779, pp. 130-131.

16. VIDAL, F. y CABASÉS, F. Reflexiones económicas sobre ciertos arbitrios de propagar la agricultura, artes, fábricas y comercio, dirigidas a los encargados y amantes del bien público. Madrid: Imp. de A. Sancha, 1781, pp. 88-89. 
pagar jornales. Es una convención recíproca entre personas que deben conocer sus intereses. Esas convenciones son libres y no debe mezclarse la ley para dirigirlas ${ }^{17}$.

A finales de siglo, las traducciones económicas prestarán argumentos añadidos a la defensa de la libertad de industria y de trabajo. En Jovellanos, Cabarrús y Foronda, se generalizan las críticas a las intervenciones públicas: la competencia, dirá este último, ha de ser «el juez imparcial que decide soberanamente el precio» ${ }^{18}$.

\subsection{Industria rural dispersa, manufacturas bastas y localización fabril}

Ya en 1724, Macanaz, en su Representación a Fernando VI ${ }^{19}$, aludía a las «Razones que acreditan los lastimosos efectos que produce en España la falta de industria popular». Años después, en 1748, Rioboo Seijas adelantaba algunos de los argumentos que más tarde hará suyos Sarmiento en defensa de la «industria rústica»: además de apelar a la economía moral de la sociedad rural, criticaba abiertamente la presencia del capital comercial a través del sistema de «adelantos» o de «venta al fiado ${ }^{20}$. Desde mediados de siglo, la multiplicación de traducciones de obras agronómicas francesas, vehículo de difusión de la funcionalidad económica de la industria doméstica familiar, venía a coincidir con la demanda de soluciones para las tensiones sociales en el campo. La elevación de las rentas agrarias y el éxodo rural incorporaron a la agenda reformista las propuestas destinadas a "arraigar» a la población campesina a través de su empleo en actividades transformadoras como vía para afianzar la estabilidad social ${ }^{21}$.

En Olavide y Campomanes, la industria doméstica en régimen de kaufsystem trataba de fortalecer la figura del labrador independiente y de evitar los riesgos de su asalarización en caso de entrar en las redes del Verlager. Aun así, no se desconocían sus limitaciones. Para Jovellanos, «aquella industria que anda unida siempre con la agricultura", aun cuando favoreciese la autosuficiencia familiar, no era la que «daba a los pueblos el nombre de industriosos y los hacía ricos». Y contraponía esta industria a las fábricas de pintados y tejidos de lienzo que dan «alimento al comercio y ofrecen útil empleo a un increíble número de brazos» ${ }^{22}$.

17. Cfr. Rodríguez Campomanes, P. Apéndice a la educación popular, III (1776). Ed. facsimilar de V. Llombart. Oviedo: Instituto Feijoo de Estudios del Siglo XVIII, 2009, p. 10.

18. Cfr. Foronda, V. de. Cartas sobre los asuntos más exquisitos de la Economía política (1788). Ed. de J. M. Barrenechea. Vitoria, 1994, p. 32.

19. Cfr. Semanario erudito, 1788, VII, pp. 150-204.

20. Vid. Dopico, F. «El proyecto económico de los ilustrados gallegos». En Fuentes QuintanA, E. (dir.). Economía y economistas españoles. 3. La Ilustración. Barcelona: Funcas, 2000, pp. 641-676.

21. Vid. Llombart, V. Campomanes, economista y politico de Carlos III. Madrid: Alianza, 1992, pp. 261-277.

22. Cfr. "Carta sobre la industria de Asturias" (1795). En Obras completas. X. Escritos económicos, cit., pp. 326-337. 
Los textos económicos abordaron igualmente cuestiones relativas a las prioridades sectoriales. A medida que se ampliaba la demanda colonial y que mejoraba la información sobre la balanza comercial de las economías que rivalizaban con la española, la preferencia por las manufacturas «finas» cedió ante la prioridad por las «bastas» o populares. Campomanes estimaba que las bayetas, sargas y sempiternas de lana salidas de Colchester, «aunque groseras, por su gran despacho son las más lucrosas a Inglaterra y las que inclinan la balanza mercantil a su favor ${ }^{23}$. Será Foronda quien mejor acierte a expresar ese giro a partir del ejemplo proporcionado por Silesia, Bretaña e Irlanda:

Si es útil al Estado trabajar cosas perfectas, no le es menos ventajoso trabajar las medianas y aún las malas con tal de que la baratura convide y provoque su consumo. El artesano ha de tener la facultad de trabajar mal y ofrecer al público obras que sean proporcionadas con las facultades del mayor número, porque de nada sirve que hagan obras perfectas sino es correspondiente su precio a la pobreza del comprador ${ }^{24}$.

Al tratar de la localización fabril, se abordó la cuestión relativa a las rentas de situación. En este punto existía unanimidad en reconocer que, más allá del emplazamiento dictado por la oferta de recursos energéticos o minerales, a las manufacturas "finas» les convenía situarse en las «poblaciones grandes»: el mayor precio de "víveres, habitaciones y demás cosas que usan las fábricas» se compensaría con los menores costes de comercialización y con la demanda derivada del mayor nivel de renta. Por el contrario, las manufacturas «bastas se labran sin dificultad casi en todas partes ${ }^{25}$. Ello no obstó para que existiesen contradictores de la ubicación urbana de las fábricas. Al respecto, señalaba Cabarrús: «Todo anuncia la ruina de la industria catalana: reunida en la mayor parte en Barcelona, ha traído una carestía excesiva que ha de inhabilitar sus producciones a la concurrencia con las extranjeras» ${ }^{26}$.

\subsection{Del atraso tecnológico al debate gremial}

Desde los ministerios de Alberoni, Patiño y Ensenada, la urgencia de modernizar arsenales y fundiciones estatales hizo patente la brecha técnica existente respecto a otras economías atlánticas y coloniales. Las comisiones científicas y de espionaje industrial -Ulloa, Jorge Juan, Morla, Casado de Torres, Sureda, Estala, Peñalver, Betancourt...- no dejaron de impulsarse desde la Secretaría de Marina

23. Cfr. CAMpomanes. Reflexiones sobre el comercio español a Indias (1762). Ed. de V. Llombart. Madrid: Instituto de Estudios Fiscales, 1988, p. 448.

24. Cfr. Cartas sobre los asuntos más exquisitos (1788-1790). Op. cit., pp. 84-85.

25. Cfr. UzTÁriz, Theórica, op. cit., cap. XCIC, pp. 334-349.

26. Cfr. Cabarrús, F. Cartas (1808). Ed. de J. M. Maravall. Madrid: Castellote, 1972, p. 153. 
en colaboración con instituciones como el Real Colegio de Artillería de Segovia o el Seminario de Bergara. En los informes y memorias de tales comisiones -visitas a los Albions Mills, al arsenal de Carrón, a la factoría de Boulton y Watt, a los principales distritos textiles y mineros ingleses...- se daban a conocer las bases energéticas y mecánicas del factory system. En 1789, Betancourt redactaba en París su Mémoire sur une machine à vapeur à doublé effect y en 1805, auspiciado por la Junta de Comercio de Barcelona, F. Santpons publicaba su Noticia de una bomba de fuego. Con desigual fortuna, desde instancias públicas y privadas, se sucedieron los ensayos de aplicar el vapor y de fundir "a la inglesa". Pese al empeño por difundir las ciencias útiles desde el Estado, el fracaso de muchas manufacturas públicas en aclimatar las tecnologías industriales, unido a las dificultades de la coyuntura finisecular, además de la aversión al riesgo, explican la escasa demanda de innovación por parte del sector privado.

Parte del atraso técnico del sector venía siendo achacado a las restricciones y "privativas» del sistema gremial. Los términos en que se debatió su reforma, salvando tiempo y distancias, recuerdan la reciente historiografía sobre «el retorno de los gremios» y las posiciones encontradas entre tradicionalistas y revisionistas ${ }^{27}$. Desde mediados de siglo, la defensa de la libertad de industria y de trabajo fue generalizándose hasta plasmarse en una legislación abolicionista -Toscana (1770), Francia (1776), Viena (1786) - cuyos ecos en España se plasmarían tanto en el marco legal como en el doctrinal. En el primer caso, con medidas de reforma que pretendían recortar las prerrogativas gremiales y sus ordenanzas, y en el segundo, con un posicionamiento mayoritario en defensa de las tesis de Campomanes -Ward, Ramos, Jovellanos, Arteta, Sistiernes...-. La excepción vendrá representada por Romá y por Capmany, abanderados de los intereses de la menestralía barcelonesa ${ }^{28}$. En ambos casos, la defensa de la "constitución" gremial se asociaba con su contribución a la articulación de un orden social dominado por las "fortunas medianas» y al fortalecimiento de una economía moral basada en el ahorro, laboriosidad y frugalidad. Desde 1780, las traducciones de Turgot y Adam Smith sirvieron para rearmar a los abolicionistas (Cabarrús, V. Alcalá Galiano, R. Campos o J. Alonso Ortiz). Para Foronda, "el efecto natural de los gremios es aumentar el precio de las obras, despojar a los ciudadanos del derecho a elegir y privarlos de la baratez ${ }^{29}$.

27. Para un estado de la cuestión, véase el monográfico: "Gremios y corporaciones laborales en la transición del feudalismo al capitalismo». Áreas. Revista Internacional de Ciencias Sociales, $2015,34$.

28. Cfr. Romá i Rosell, F. Disertación histórico-político-legal por los Colegios y Gremios de la ciudad de Barcelona y sus privativas (1766); CAPMAnY, A. Discurso económico-político en defensa del trabajo mecánico de los menestrales y de la influencia de los gremios en las costumbres populares, conservación de las artes y honor de los artesanos (1778), publicado bajo el seudónimo de R. M. de Palacio y reeditado anónimamente en 1788 como Discurso político-económico sobre la influencia de los gremios en el Estado, en las costumbres populares, en las artes y en los mismos artesanos.

29. Cfr. FORONDA (1788). Op. cit., pp. 49-50. 


\subsection{De la Économía política a la política industrial}

En 1952, Vicens Vives atribuía el éxito del colbertismo en economías periféricas como la española al retraimiento de la iniciativa empresarial privada y a las imperfecciones en el funcionamiento de los mercados y en el marco institucional. El cameralismo germánico suministró argumentos añadidos a las intervenciones públicas destinadas a favorecer la convergencia con las «naciones industriosas ${ }^{30}$. En cualquier caso, la valoración de las políticas económicas del reformismo borbónico ha merecido interpretaciones encontradas ${ }^{31}$. En el caso de las industriales, las diferencias interpretativas se han centrado en tres aspectos: en la inutilidad de buscar un nexo evolutivo que conduzca linealmente del mercantilismo al liberalismo, pues las políticas aplicadas combinaron protección exterior y liberalización interior; en las limitaciones que a tales políticas impusieron bien las medidas arancelarias exigidas por los tratados comerciales, bien el juego de intereses sectoriales contrapuestos -caso, por ejemplo, de las posiciones de los cosecheros de lana o seda frente a los fabricantes-; finalmente, y desde una perspectiva doctrinal, se ha enfatizado la dificultad de formular una política industrial coherente dada la carencia de una previa teoría del crecimiento $^{32}$.

Para los arbitristas toledanos, la «restauración» de la industria española vendría del «radical remedio de vedar las mercaderías labradas en el extranjero» ${ }^{33}$, unido a una revisión de la fiscalidad interior, responsable, según Martínez de Mata, de la "aniquilación de las fábricas». Los argumentos citados serían revisados por Uztáriz, partidario de "franquicias y exenciones" -en "los comestibles que consumen los operarios y en los materiales que emplean»- y de unos "arreglados" aranceles: «Lo bueno que viene de fuera sirve de conocimiento, emulación y estímulo para mejorar»" ${ }^{34}$. En la Theórica dedicaba 21 capítulos a las «Diversas resoluciones, reglamentos y providencias para auxiliar y adelantar los comercios y manufacturas», con numerosos comentarios a situaciones sectoriales y regionales. En igual sentido, Ulloa, en el noveno capítulo de su Restablecimiento de las fábricas (1740) - «En que se manifiesta que los precios altos de los tejidos de España lo causa la carestía de abastecimientos»-, criticaba al peso de alcabalas, cientos, portazgos, aduanas y

30. Cfr. Lluch, Ernest. "El cameralismo en España». En FuENTES Quintana, E. (dir.). Op. cit., 1999, pp. 721-760.

31. Para una síntesis, Llombart, V. "La política económica de Carlos III: efiscalismo, cosmética o estímulo al crecimiento?». Revista de Historia Económica, 1994, 1, pp. 11-39, y «Economía política y reforma en la Europa mediterránea del siglo XVIII: una perspectiva española». En SCHWARTZ, P. (coord.). Mediterráneo Económico, 2006, 9, pp. 95-113.

32. Cfr. BREwer, A. "The concept of growth in Eighteenh-Century Economics". History of Political Economics, 1995, vol. 27, 4, pp. 609-638.

33. Vid. Moncada, S. de. Restauración política de España (1619). Ed. de J. Vilar. Madrid: Instituto de Estudios Fiscales, 1974.

34. Vid. FERNÁNDEz DuRán, R. Gerónimo de Uztáriz (1670-1732): Una política económica para Felipe V. Madrid: Minerva, 1999, pp. 121-122. 
arbitrios municipales, si bien el límite de la presión fiscal lo condicionaba a que no se experimentase «un gran decaimiento de las Rentas Reales" ${ }^{35}$.

En la segunda mitad del siglo la recepción del mercantilismo liberal -Child, Davenant- y de la aritmética política amparará nuevos posicionamientos doctrinales: "Sin vasallos ricos no puede haber Erario poderoso», dirá Gándara. Para Romá, «la pérdida de algunos derechos queda bien compensada cuando es medio de que se fomenten otros ramos que aumentan de varios modos el número de contribuyentes ${ }^{36}$. Arriquibar estimaba en un $35 \%$ el recargo o sobrecoste que los impuestos suponían para las manufacturas españolas frente a las extranjeras ${ }^{37}$.

Uztáriz había sido pionero en la revisión crítica del sistema arancelario al dedicar 24 capítulos de la Theórica a explicar las políticas con que Francia e Inglaterra "han sabido hacer florecer y conservar" su comercio y riqueza, contraponiéndolas a la "ceguedad» de las ordenanzas españolas y al problema añadido que suponían el fraude fiscal y el contrabando. Desde entonces, se generaliza la opinión de que una buena política arancelaria debería estar al servicio de la industrialización y no de la recaudación. Para Ward,

El objeto de las aduanas e imposición de tributos, en su primera institución, se dirigió a dar réditos al Príncipe; esto fue en la infancia de la verdadera política. Un siglo entero costó a los hombres más grandes de Francia, Inglaterra y Holanda buscar un justo temperamento en la imposición de los tributos, de modo que ni las fábricas ni el comercio ni las artes llevasen una carga desproporcionada ${ }^{38}$.

En las Reflexiones sobre el comercio español a Indias (1762), Campomanes, analizando lo que él mismo bautizaría como «revolución mercantil» británica, acierta a contextualizar cómo el giro que las economías europeas venían imprimiendo a sus aranceles no hacía sino reflejar la transición del capitalismo mercantil al industrial $^{39}$. En el caso español era preciso considerar, además de los aranceles, los "favores exorbitantes" derivados de los tratados comerciales firmados con Francia e Inglaterra ${ }^{40}$.

35. Op. cit., p. 33

36. Las citas en GÁndara, M. A. Apuntes sobre el bien y el mal de España (1759). Ed. de J. Macías Delgado. Madrid: Instituto de Estudios Fiscales, 1988, p. 96, y en Romá I Rosell (1768), Las señales..., op. cit., pp. 184-185.

37. ARRIQUibar (1779), op. cit., p. 232.

38. Cfr. WARD (1779), op. cit., pp. 197-198. Reflexiones similares se encuentran en las obras de Gándara y Campomanes. Para Gándara, las aduanas eran "la Economía política de la circulación»: $c f r$. (1759), op. cit., pp. 31-34.

39. Vid. LlOMBART, V. "Estudio preliminar". En Campomanes: Reflexiones sobre el comercio español a Indias (1762), op. cit., pp. 22-41.

40. Cfr. Canga Argüelles, J. Diccionario de Hacienda. Madrid, 1833, II, pp. 131-133; FernándeZ DE PINEDO, E. «Notas al comercio de exportación español en la primera mitad del siglo XIX (1792-1842)». En Doctor Jordi Nadal [homenaje]: la industrialización y el desarrollo económico de España. Universitat de Barcelona, 1999, I, pp. 608-627. 
Aun cuando la recepción de Adam Smith abriese el camino a una concepción liberal de la tributación apoyada en los principios de proporcionalidad y universalidad $^{41}$, la "adaptación razonada" (Almenar) de La riqueza y de sus críticas al «sistema mercantil» no estuvo reñida con la aceptación del proteccionismo industrial para economías periféricas como la española. Como acertó a expresar Lázaro de Dou en La riqueza de las naciones nuevamente explicada (1817), "cuanto más lejos está una nación de igualar y superar a las otras en industria, tanto más lejos debe estar de adoptar el sistema de Smith».

\section{ECONOMÍA POLÍTICA Y MANUFACTURAS: LAS RESPUESTAS REGIONALES}

En el Discurso sobre el fomento de la industria popular (1774), Campomanes, al referirse a las políticas industriales, señalaba que "no es accesible a ningún gobierno velar en cosas tan extendidas», de ahí su apelación a la actuación subsidiaria de las Sociedades Económicas en las labores de fomento fabril. Además de confeccionar la "historia económica de la provincia», de dar "noticia de las fábricas perdidas" y de la posibilidad de restablecerlas, su agenda incluía la institucionalización de premios a artesanos o campesinos que mejorasen la productividad del trabajo; la traducción y divulgación de tratados técnicos sobre industrias, máquinas, tintes, materias primas, y, en general, cualquier iniciativa que, alejada de "especulaciones abstractas", se fundase "en el conocimiento real» de cada sector. Dada la composición social de las Sociedades, nada tiene de extraño que se priorizasen aquellos objetivos tendentes a fortalecer la estabilidad en el mundo rural y urbano. Al hacerlo, restringían el alcance de la "educación popular» a objetivos congruentes con tal prioridad: fijación y "arraigo" de la población rural, reducción del subempleo estacional y de la ociosidad, y fomento de la pluriactividad en las economías familiares.

Consulados, audiencias, juntas de comercio, academias o seminarios, condicionados por su dotación de medios y composición social, se sumarán a las propuestas industrializadoras gubernamentales. Y, sin embargo, pese a las recomendaciones oficiales, tanto el discurso salido de la Economía política como el del reformismo oficial serán objeto de reformulación, enmienda o adaptación en función de las circunstancias económicas específicas de cada territorio -dotación de recursos, ventajas competitivas, trayectorias empresariales previas...- o de los intereses sociales representados en aquellas corporaciones. Es lo que se tratará de analizar a partir de los casos regionales que se exponen a continuación ${ }^{42}$. Más que

41. "Los ricos deben ser mucho más recargados que el artesano, el oficial o el jornalero, que solo ganan para el alimento de su familia»: cfr. Alcalá Galiano, V. Sobre la Economía política y los tributos (1781). Ed. de J. M. Valles Garrido. Segovia, 1992, p. 255.

42. Vid. LlopIS, E. «El legado económico del Antiguo Régimen desde la óptica regional». En GERMáN, L. et al. (eds.). Historia económica regional de España (s. XIX y XX). Barcelona: Crítica, 2001, pp. 507-524. 
los resultados económicos, se enfatiza el papel de las instituciones y sus propuestas o modelos de desarrollo manufacturero, así como las respuestas empresariales a los mismos.

\subsection{Las provincias «exentas»: restricciones forales a la industria}

El patriotismo inspira, la Economía política investiga, y la industria ejecuta (Peñaflorida, 1779) ${ }^{43}$.

La "nobleza comerciante» vasca, a través de la Bascongada y del Seminario de Vergara, aspiró a vertebrar una vía de crecimiento adaptada a la "constitución" del país ${ }^{44}$. En el título quinto de los estatutos de la Sociedad se señalaba la necesidad de «establecer en las tres Provincias todas las manufacturas del hierro y del acero que, entabladas ya, admiten todavía mucha perfección y economía ${ }^{45}$. Tal propuesta partía del carácter estratégico otorgado a la siderurgia -«un ramo sin el cual perecerían estas provincias»- y del reconocimiento del desfase técnico del sector y de su poco competitiva estructura de costes -factor, este último, que, junto al régimen aduanero foral, contribuía a explicar el desplazamiento de los hierros vascos por los suecos y rusos en los mercados europeo y colonial-. Es en este contexto en el que cobran sentido los trabajos de la "Comisión de Ciencias y Artes Útiles". En los 23 tomos de sus Extractos (1771-1793), se recogían memorias y estudios sobre coste y rentabilidad del proceso productivo (calcinación de venas, dotación forestal, tipología de hornos...), sobre experiencias de transferencia tecnológica (hojalata, carbón mineral, acero) y sobre las investigaciones de los técnicos extranjeros (Elhuyar, Dowling, Proust). La Bascongada patrocinó igualmente comisiones científicas y de espionaje industrial en los establecimientos mineros y fundiciones europeas, caso del «viaje al norte» de Munibe en $1770^{46}$.

Con el "Proyecto de Escuela Patriótica» (1775), la Sociedad aspiraba a formar técnicos en mineralogía y metalurgia con vistas a preparar la incorporación de

43. "Introducción a la Asamblea General de la Real Sociedad Vascongada». En MuniBE, J. de (conde de Peñaflorida). Discursos inéditos (1779). Ed. de J. Astigarraga. Vitoria: Ararteko, 2002, p. 185.

44. Vid. Astigarraga, J. Los ilustrados vascos: ideas, instituciones y reformas económicas en España. Barcelona: Crítica, 2003.

45. Real Sociedad Vascongada de los Amigos del País. Extractos aprobados por S. M. para el gobierno de la Real Sociedad Bascongada de los Amigos del País (1764-1775). San Sebastián: Sociedad Guipuzcoana de Ediciones, 1985, I, p. 37.

46. En su Noticia de las ferrerías de Suecia (1772), recogida en los citados extractos, escribiría: "En nuestro país no se sabe casi nada de lo que se llama trabajo en grande del fierro, pues no se hace más que seguir el uso y costumbre de los antiguos. Si vemos que nuestras ferrerías arruinan muchas veces al dueño y al arrendador, debemos atribuirlo a ciertos métodos cuya falta conocerá a primera vista un químico de mediana inteligencia. Por ahora, solo puedo decir que este defecto es irremediable en el sistema que se sigue en nuestro país...». 
«máquinas y bombas» que mejorasen la rentabilidad de minas y fundiciones ${ }^{47}$. Años después, un informe de F. de Elhuyar sobre el Estado de la minería de Somorrostro (1782) evidenciaba la falta de "reglas» en los arranques y acarreos, la ausencia de facultativos y de "geometría subterránea", así como las limitaciones derivadas del régimen de propiedad y explotación de las minas. Pese al nivel alcanzado en los estudios científicos, el desfase entre objetivos y resultados, así como la falta de eslabonamientos entre ciencia básica y aplicada, resultaron insalvables.

Pero, más allá de todas estas propuestas, se admitía que la suerte industrial de la región se vinculaba al régimen foral. Por ello, la ofensiva centralizadora del Gobierno -exclusión de los puertos vascos de la habilitación (1778), imposición de derechos de extranjería (1779) a las mercancías vascas que se internasen en los mercados castellanos- será objeto de rechazo por parte de las Juntas Generales vascas y de las Cortes navarras. Un rechazo que dejaba en mal lugar los programas industrialistas de la Ilustración vascongada frente a los intereses comerciales de la «nobleza comerciante». En efecto, desde la guerra de Sucesión, las poderosas casas de comercio vasco-navarras -curtidas en contratos y asientos de suministro al ejército y la marina, en el arriendo de estancos, en la banca y exportaciones de vellón o en las operaciones de consignación y comisión por cuenta de compañías extranjeras- habían tejido amplias redes clientelares que se extendían desde Bilbao, Navarra y San Sebastián a Madrid y Cádiz ${ }^{48}$. Del mismo modo, las aspiraciones empresariales donostiarras se orientarán, una vez constituida la Compañía de Caracas, hacia el comercio colonial. Una opción mercantil, frente a la fabril, que acertó a expresar J. A. de los Heros:

Preguntemos en la Montaña, Vizcaya, Navarra, ¿quién ha reedificado las casas solares de los más ilustres defensores de la Religión, Rey y Patria, sino los hijos de aquellos pueblos que, desprendidos en tierna edad, han hecho fortuna por el comercio? ${ }^{49}$.

Como en el caso vasco, desde la Sociedad Tudelana de los Deseosos del Bien Público (1778), el marqués de San Adrián -Discurso sobre el fomento de la industria (1782), Informe sobre las fábricas del Reino (1785)- sostenía la incompatibilidad del desarrollo fabril con el régimen aduanero vigente ${ }^{50}$. Algo similar ocurrirá con los vinos: la inhabilitación para el comercio colonial obligará a la Tudelana a proponer mercados mediterráneos en su Extracto sobre las ventajas de la

47. Vid. Silván, L. Los estudios científicos en Vergara a fines del siglo XVIII. San Sebastián, 1953.

48. Cfr. Angulo Morales, A. "Bilbao, Madrid, Londres: Ganaderos, comerciantes y cambistas vascos en los mercados financieros y laneros del Atlántico»; GonZÁlEz ENCISO, A. "Empresarios navarros en el siglo XVIII»; Imizcoz, J. y GUERRERO EleCAlDE, R. «Negocios y clientelismo político: los empresarios norteños en la monarquía borbónica». En OCAMPO SuÁREZ-VAldÉs (ed.). Op. cit., pp. 183-210, 297-331 y 331-362, respectivamente.

49. La cita en Angulo Morales. Op. cit., pp. 189-190.

50. Vid. Astigarraga, J. "La Sociedad Económica de Navarra en la segunda mitad del siglo XVIII». Gerónimo Uztáriz, 1992, 6-7, pp. 25-78. 
exportación de vinos. Los bloqueos existentes explican la diáspora de los empresarios protagonistas de la "hora navarra", caso de los Goyeneche, Uztáriz, Mendinueta, Valdeolmos, Arizcun...

\subsection{La Montaña y Asturias}

Liérganes, La Cavada y Trubia, así como las Reales Empresas Mineras del Nalón, protagonizaron al primer ensayo de transferencia tecnológica con vistas a adoptar la "fundición a la inglesa" en altos hornos alimentados por carbón mineral. Todo ello en un escenario dominado tanto por limitaciones estructurales derivadas de los altos costes del carbón vegetal y de la dependencia de las importaciones británicas, como por las urgencias coyunturales: guerra contra la Convención francesa (1793-1795), destrucción de las fundiciones pirenaicas y ocupación de las armerías vascas.

\subsubsection{La Montaña: del alto borno a la harinería}

En las fundiciones de artillería y municiones de Liérganes y La Cavada, los asientos con la Corona y los privilegios asociados a los mismos constituyeron una vía segura para consolidar beneficios a costa de evitar riesgos de innovación. Su paso en 1763 a la Secretaría de Guerra, y en 1781 a la de Marina, coincidirá con los fracasados esfuerzos por mejorar la fundición de cañones en hueco y en sólido y por ensayar el uso del carbón mineral ante el agotamiento de las dotaciones forestales de ambos establecimientos ${ }^{51}$. Con anterioridad, otro establecimiento público, el Real Astillero de Guarnizo, había corrido similar suerte: la imposibilidad de competir fuera del marco privilegiado. Cantabria volvía a depender del comercio, pues «el comercio la sacó de la nada» ${ }^{52}$ o, como dirá Manso,

En esta provincia, no hay Academias ni Sociedades científicas que puedan comunicar nuevas ideas. El Consulado, los que hoy están a su frente, todos comerciantes, carecen absolutamente de ideas sobre economía pública. El fomento de las fábricas y artes con que se alimenta el comercio, no entra en su limitado plan de conocimientos $^{53}$.

51. Cfr. Helguera QujJada, J. «De La Cavada a Trubia. Intervención estatal y cambio tecnológico en las fundiciones de artillería del Norte de España». En OcAmpo SuÁrez-VAldés, J. (ed.), 2012, op. cit., pp. 153-181.

52. Expresión de viajero alemán Kaufhold a su paso por Cantabria: cit. en MARuRI ViLLANuEva, R. y MAISO GONZÁLEZ, J. "Iniciativas empresariales y modernización económica en la Cantabria del siglo XVIII». En OCAMPO Sú́reZ-VAldés (ed.), 2012, op. cit., pp. 123-153.

53. Cit. en MANSO, J. Estado de las fábricas, comercio, industria y agricultura en las montañas de Santander (1798). Ed. de T. Martínez Vara. Santander: Estudio, 1979, p. 285. El manuscrito de Manso 
La segunda oportunidad volvía a llegar de la mano de la intervención pública: la apertura de la carretera real de Reinosa (1753), el Consulado y la habilitación para el comercio colonial (1778) reforzaban la función redistribuidora -lanas, trigo, vinos castellanos, géneros coloniales- del puerto de Santander, ahora con acceso a Palencia y Burgos. En el último cuarto del siglo se multiplican las fábricas de harina a lo largo de la cuenca del Besaya, a la vez que navieros y armadores vascos y santanderinos diversifican inversiones: curtidos, cerveza, refino de azúcar y mantequerías. En 1792 se registraba en Torrelavega el primer ensayo de fábrica de hilados de algodón a cargo del duque del Infantado.

\subsubsection{Asturias: de "Siberia del norte» $a$ "Sajonia española"}

Transformar un país aislado, rural y pobre en un poderoso distrito minero y fabril fue el sueño que inicialmente Jovellanos depositó en las posibilidades abiertas por la explotación del carbón mineral. El interés científico y económico por el fósil fue visible desde 1770, coincidiendo con los primeros desembarcos de hulla inglesa en diferentes puertos españoles y con la instalación en La Cavada de hornos de reverbero para experimentar con el mismo ante los prohibitivos costes del carbón vegetal. En el año citado, la Secretaría de Marina iniciaba la explotación de las cuencas hulleras de Siero y Langreo. Por las mismas fechas, Campomanes, en el Apéndice tercero a la educación popular (1776), daba a conocer tres obras sobre el "Arte de beneficiar el carbón e piedra con aplicación a la fabricación de hierro». En la misma dirección, en la Sociedad Económica se sucederán los informes divulgativos sobre minería. En uno de ellos, el conde de Toreno daba a conocer la memoria de Betancourt ya citada. En 1786, se realizaban sin éxito los primeros ensayos de "purificación" del carbón mineral. Un perspicaz Townsend, de viaje entonces por Asturias, apuntaba que "por el momento no se encuentran alicientes para explotar las minas, pues la zona es rica en maderas». Se refería al sector privado.

En 1789, Jovellanos se traslada a Asturias como comisionado de minas. Entre aquel año y 1797 redacta los Informes mineros. En ellos, a menudo en contradicción con las tesis mantenidas desde la Secretaría de Marina, abordaba tanto cuestiones técnicas ("geometría subterránea", arrastres), como legales y empresariales (derechos de propiedad, titularidad, gestión) y de transporte (¿canalización del Nalón o carretera carbonera?). La coyuntura abierta en 1793 acelerará los proyectos industriales de la Marina en Asturias: Fábricas de Trubia, Minas de Langreo y Empresa del Nalón.

Los Informes mineros constituyen la mejor crónica de la quiebra de los citados proyectos: desde 1801, se volvía a fundir con carbón vegetal y desde 1803 se

ha sido objeto de revisión crítica por SÁnchez Gómez, M. (ed.). Antonio Diego de Tricio: La Montaña en 1784: Informe a la Junta de Comercio y Moneda. Universidad de Cantabria, 2007. 
abandonaba el transporte fluvial. Faltaban «luces, auxilios» y «capitalistas». En 1795, Jovellanos sostenía que la única viabilidad comercial para el carbón asturiano vendría de la demanda externa, de ahí su iniciativa para el Instituto de Náutica y Mineralogía y sus propuestas para mejorar la infraestructura portuaria de Gijón e incentivar la construcción de una flota mercante carbonera. En su Carta sobre la industria de Asturias (1796), un Jovellanos pesimista y consciente de que las ventajas competitivas ligadas a la dotación de recursos son meras facilitadoras del crecimiento, pero no condición suficiente, volvía la vista hacia el sector manufacturero para insistir en los mismos estrangulamientos que restringían su desarrollo: escasa dimensión del mercado interior, aislamiento geográfico, altos costes de transporte, tendencia del capital comercial a volverse "terrazguero".

\subsection{Galicia: sociedad tradicional y "frente antiindustrialista»}

La industria rural doméstica incluía "actividades de auxilio» que constituían un componente esencial de la renta campesina. Las instituciones representativas de la Ilustración gallega -Academia de Agricultura, Sociedades Económicas de Santiago y Lugo, Consulado de La Coruña...- no fueron ajenas a la precariedad de lo que Campomanes calificara como «benéfica constitución económica». La pretensión de la Academia de Agricultura de perfeccionar los «instrumentos rústicos» y de aplicar al campo «ingenios que aumentasen la labor a menos costa» no tardó en recibir severas críticas por parte de ilustrados como Sarmiento ${ }^{54}$ :

Quién persuadirá a los labradores gallegos que les será útil una Academia de Agricultura donde los más son hombre de pleitos y pluma que no saben ni una palabra de la lengua gallega, tan precisa para hablar con los labradores...

Las Sociedades de Lugo y Santiago centraron sus esfuerzos en el ubicuo ramo de la lencería doméstica. Un sector cuya debilidad competitiva derivaba tanto de las fases de cultivo y preparación de la materia prima, como del proceso de blanqueo y de la propia organización productiva, aspectos a los que se referirá Cónsul Jove en su difundida Memoria físico-económica sobre el mejoramiento de los lienzos (1792). Mejor suerte correrían las iniciativas del Consulado de La Coruña y de la burguesía mercantil de la ciudad, espoleadas por el establecimiento de la Sociedad de los Correos Marítimos (1764) y sus eslabonamientos hacia atrás (astilleros, fábricas de jarcia y lona, ferrería...) y hacia delante (producción lencera, créditos y seguros, curtidos). En este contexto, los intereses presentes en el Consulado protagonizaron esfuerzos modernizadores que no tardaron en hallar oposición. Riobóo Seijas y Sarmiento exteriorizaron su temor a que compañías de comercio

54. Cfr. "Obra de los 660 pliegos" (1762): cit. en Dopico, F. A Ilustración e a sociedade galega: A visón dos ilustrados. Vigo: Galaxia, 1978, p. 49. 
y fabricantes-comerciantes acabasen con la independencia de la industria "rústica»: el "poner fábricas de lienzos será destruir Galicia, quitando que cada uno la pueda tener en su casa» y poniendo en riesgo «lo mejor que hay en aquel Reino, que todas las mujeres trabajan para sí y que no pasen a ser jornaleras " ${ }^{55}$. Como señalará Lucas Labrada, las causas alegadas por los antiindustrialistas, además de «opuestas a los principios de la economía civil", venían a probar que el establecimiento de fábricas eran «empresas muy arriesgadas cuando hay que combatir preocupaciones y disipar tinieblass ${ }^{56}$. Dadas las resistencias apuntadas, el Consulado dirigirá su atención hacia un sector manufacturero nuevo y no regulado, el del algodón, que desde 1770 había conocido distintos ensayos para el establecimiento de indianas y pintados. Sin embargo, las dificultades finiseculares -crisis agraria y colonial, contrabando inglés, competencia catalana...- acabarán abortando buena parte de los proyectos empresariales.

Factores coyunturales al margen, el fracaso industrializador apuntaba, más que a la falta de empresarios o de capitales, a las relaciones sociales vigentes y a las propias estrategias del capital comercial $^{57}$. En este sentido, las resistencias antiindustrialistas no eran nuevas. Habían tenido ocasión de manifestarse con la presencia, desde 1760, de los "fomentadores" catalanes en el sector pesquero y conservero. La renovación de las técnicas extractivas -sustitución de xeitos por jabegas de arrastre- y de salazón por ellos introducidas venía a cuestionar el tradicional equilibrio en que venía desenvolviéndose el sector bajo el control de los gremios de mareantes ${ }^{58}$. En 1774, Cornide Saavedra abanderado del "frente» anticatalán, escribía:

Vivía Galicia en el seno de la paz y de la abundancia, y he aquí que se presentan los industriosos catalanes, esos holandeses del mediodía, esos especuladores cuyas operaciones dirige solo el interés ${ }^{59}$.

Era la misma "fortaleza» y resistencia del orden social tradicional que tendrá ocasión de expresarse con máxima crudeza con ocasión del motín que en 1798 arrasaba las fundiciones de Antonio Raimundo Ibáñez en Sargadelos (Cervo, Lugo).

55. Cfr. CARMOna J. El atraso industrial de Galicia, Auge y liquidación de las manufacturas textiles (1750-1900). Barcelona: Ariel, 1990, pp. 53-54.

56. Cfr. Labrada, L. Descripción económica del Reino de Galicia (1804). Ed. de F. Río Barja. Vigo: Galaxia, 1971, pp. 213-214.

57. Vid. CARMONA (1990), op. cit., pp. 171-180. En el caso de Cantabria, Diego de Tricio culpaba del ocaso de las manufacturas a la disociación entre capital mercantil e industria: «... en aquellos siglos felices, cuando en España floreció la industria, los fabricantes eran mercaderes a un mismo tiempo": cfr. TRICIO, op. cit., p. 115.

58. Vid. Alonso Álvarez, L. Industrialización y conflictos sociales en la Galicia del Antiguo Régimen, 1750-1830. Madrid: Akal, 1977.

59. Cfr. OCAMPO SuÁrEZ-VALDÉs, J. «Los catalanes en España y la Economía política de la Ilustración: ¿“Conquista pacífica” o "Españas vencidas”?». Revista de Historia Moderna, 2010, 29, pp. 185-203. 
2.4. "Del vasto territorio y la escasez de hombres" ${ }^{60}$ : la España interior y agraria

\subsubsection{Castilla: de la lana al textil, del trigo a la "molienda económica"}

En Castilla-La Mancha, el modelo agrícola imperante explica en buena medida que cualquier iniciativa fabril tuviera "más de voluntarismo que de opción realista " ${ }^{61}$. La recuperación manufacturera del XVIII compensó parcialmente la "desindustrialización» del siglo anterior. Una recuperación que se vería favorecida por el estímulo estatal que supusieron las Reales Fábricas textiles (Guadalajara, Toledo, Talavera, Pastrana, Cuenca y Almagro), mineras (Alcaraz, El Salobre, Almadén) y de carácter militar (fábrica de pólvora de Ciudad Real y de armas blancas de Toledo), además de las manufacturas privilegiadas de las Compañías de Comercio. La suerte de tales establecimientos, vinculada al presupuesto público y a privilegios y franquicias, no superará la crisis fiscal finisecular. Ni la proximidad al mercado madrileño ni las favorables condiciones de acceso a la materia prima o la oferta de mano de obra barata permitieron compensar la escasa competitividad de sus producciones.

Al margen de la manufactura concentrada, la pañería castellana se hallaba reglamentada por las Ordenanzas Generales del Obraje de Paños (1511), que consagraban la figura del Verleger o "dueño de paños" a la par que reglamentaban los oficios textiles agremiados. Dada la dispersión de talleres, los comerciantesfabricantes, que limitaban su intervención al control de las fases finales del trabajo (cardado, tundido), aceptarán de buen grado el control gremial sobre el proceso productivo en la medida en que garantizaba la estandarización y calidad de los paños a costa de sacrificar la innovación ${ }^{62}$.

Entre la docena de Sociedades Económicas fundadas en la región, la de Segovia fue sin duda la más activa ${ }^{63}$. Desde su creación en 1781, incorporó a los

60. Reproduce el título del trabajo de DoBAdo, R. y López, S. «Castilla-La Mancha: del vasto territorio y la escasez de hombres». En Germán, L. et al. (eds.), op. cit., 2001, pp. 238-270.

61. Dobado y López. Op. cit., p. 233

62. Los "fabricantes sin fábrica» participaron en la reforma de las Ordenanzas de 1733 -ordenada en 1780 por el Consejo de Castilla- que constituían el instrumento del que se servían los gremios de la "Fábrica común" para imponer un modelo productivo al que se responsabilizaba de la pérdida de competitividad del sector. Los fabricantes venían reclamando liberalizar el uso de las lanas empleadas como materia prima, así como la "economía de las maniobras» y la adaptación al mercado de las calidades producidas. La aprobación en 1789 de un nuevo reglamento sería bien valorada por la Sociedad: la manufactura textil "ya no gime bajo aquella esclavitud a que estaba sujeta, y goza al presente de aquella libertad que es tan necesaria para que prospere cualquier manufactura». Cfr . GARCÍA SANZ, A. "Industria textil tradicional y las reformas de la Ilustración: las transformaciones de la pañería segoviana durante el reinado de Carlos III". En Carlos III y la Ilustración. II. Economía y Sociedad. Madrid: Ministerio de Cultura, 1989, pp. 363-389.

63. Vid. VAllés Garrido, J. M. (ed.). "La Real Sociedad Segoviana de Amigos del País en el siglo XVIII. En Los Estatutos de la Real Sociedad de Amigos del País de la ciudad de Segovia (1781). Segovia, 1996. 
fabricantes del sector lanero, así como a los profesores del Real Colegio de Artillería -V. Alcalá Galiano, Proust, Munarriz y García de la Huerta, entre otros-. La presencia de los Verlager obedecía a su interés por la renovación de las técnicas de blanqueo y tintado de lienzos y, en menor medida, por la mecanización de los procesos de trabajo, si bien en este caso, y salvando la manufactura concentrada de Ortiz de Paz, no se trataba de una prioridad. En materia de tintes, se contaba con la colaboración de Proust y de García de la Huerta. En cuanto a máquinas, además de una de hilar diseñada por A. Bartolomé Pérez, se presentó un modelo de lanzadera enviada desde Londres por Tomás de Morla en cuyos Apuntes autógrafos ofrecía abundantes noticias sobre los distritos laneros de Lancaster y Yorkshire y sobre las fábricas de indianas de Glasgow y Mánchester. Por otro lado, las relaciones entre la Sociedad y el Colegio de Artillería permitieron desarrollar un ambicioso programa de divulgación científico-técnica -trabajos de Vicente Alcalá Galiano sobre electroterapia y meteorología, de García de la Huerta sobre experimentación agrícola, de Proust sobre materia tintes, etc.-, calificado por Vallés Garrido de «ingenuamente cientifista» por su escasa proyección económica.

En Castilla-León el desarrollo manufacturero tuvo más de recuperación que de crecimiento. El textil de Segovia, Valladolid, Burgos y Palencia, que lideraba la producción nacional, ofrecía dos subsectores diferenciados. El de la pañería de calidad -Ortiz de Paz (Segovia), Salernou (Ávila), Bejar-, orientado a la demanda de los grupos rentistas, hubo de padecer la competencia catalana y extrajera, ambas dotadas de potentes redes comerciales. La pañería popular conoció «nebulosas industriales» en torno a la Tierra de Campos (Astudillo, Frechilla, Villada), Segovia (Bernardos, Riaza), Salamanca (Peñaranda de Bracamonte, Lumbrales) y Cameros (Enciso, Ezcaray, Torrecilla). La falta de proyección industrial del sector ha sido achacada al contrabando textil, a la competencia catalana, a la rigidez gremial y a la falta de compromiso inversor de una burguesía rural que vinculaba sus beneficios al comercio de cereales y lana, al arrendamiento de impuestos y diezmos, o a la introducción de géneros coloniales ${ }^{64}$. También aquí, como en Castilla-La Mancha, el textil conoció ensayos de manufactura concentrada. Entre la media docena de Reales Fábricas, la de Algodón de Ávila (1788) supuso el proyecto más prometedor: la Secretaría de Hacienda invirtió en la misma 12 millones de reales e incorporó a tejedores suizos, estampadores catalanes y maquinistas ingleses. Los

64. Vid. Yun Casalilla, B. "Mercado de cereal y burguesía en Castilla, 1750-1868 (Sobre el papel de la agricultura en el crecimiento económico regional)", y GARCía COLMENARES, P. "De la desindustrialización del sector textil lanero castellano a la creación de pequeños centros industriales: Palencia, 1780-1930». En Yun Casalilla, B. (coord.). Estudios sobre capitalismo agrario, crédito e industria en Castilla (siglos XIX y XX). Salamanca: Junta de Castilla y León, 1991, pp. 47-76 y 131-159, respectivamente. HERnÁNDEZ GARCíA, R. "La industria textil lanera en Castilla y León en el siglo XIX: la inadaptación a un nuevo modelo empresarial». En Comín, F.; Hernández, R. y Moreno, J. (eds.). Instituciones políticas, comportamientos sociales y atraso económico en España, 1500-2000. Salamanca: Ediciones de la Universidad de Salamanca, 2017, pp. 267-286. 
costes de adquisición y transporte de la materia prima, el exceso de plantilla y la escasa salida de su producción en Madrid y Cádiz marcaron la suerte de la fábrica, traspasada en 1799 a Agustín de Betancourt, que la gestionará entre 1800 y 1807 sin demasiado éxito ${ }^{65}$. Otros ensayos y tentativas -Real Fábrica de lienzos de León (1751), Compañía de Comercio y Fábricas de San Carlos de Burgos (1767)...- no corrieron mejor suerte ${ }^{66}$.

La iniciativa fabril con mayor futuro económico crecerá a la sombra del interés gubernamental por sustituir en el mercado colonial las importaciones de harina británica. La apertura del "camino de las lanas» entre Burgos y Santander por Reinosa (1753), el avance de las obras del ramal de Campos del canal de Castilla y la habilitación del puerto de Santander explican -junto a la concesión de privilegios para el acceso a la materia prima- la presencia de capitales comerciales vascos, cántabros y castellanos en la creación de las fábricas en que se ensayará la "molienda económica" -las de Grijota, Monzón de Campos, Aguilar de Campoo y Villalumbrosa- ${ }^{67}$, una presencia que se repetirá en la caso de los curtidos -Melgar de Fernamental (1768), Herrera (1806) - y el papel.

En Madrid, los proyectos colbertistas de la Corona -Reales Fábricas de tapices, vidrios, espejos o porcelanas de San Ildefonso, Santa Bárbara, Buen Retiro o San Fernando-, si bien contribuyeron a sustituir importaciones o a cualificar al artesanado en ellas empleado, al limitar su oferta a un mercado restringido generaron escasas economías externas. Las rentas de situación atrajeron hacia el sector capitales procedentes del comercio que, más que proyectos innovadores, buscaban hacerse con los asientos públicos y con las redes de abastecimiento y comercialización de las manufacturas concentradas existentes ${ }^{68}$. Todo ello explicaría que, a diferencia de Barcelona o Londres, Madrid actuase más como centro comercial y succionador de recursos castellanos que como un moderno núcleo industrial transformador ${ }^{69}$.

Bajo el patrocinio de la Matritense, el impulso a las manufacturas se canalizó a través de dos tipos de centros formativos: por un lado, aquellos que, como las escuelas de Mecánica (1775) y de Relojería, limitaron su alcance al perfeccionamiento del trabajo artesanal agremiado en el sector de las manufacturas "finas"; por otro, el de las «escuelas-fábrica» o "patrióticas» que aspiraban a extender la

65. Vid. Martín García, G. La industria textil en Ávila durante la etapa final de Antiguo Régimen: la Real Fábrica de Algodones. Ávila: Diputación Provincial, 1989.

66. Vid. HElguera QujJada, J. «Un empeño fallido de reindustrialización: las Reales Fábricas del siglo XVIII en Castilla y León». En Comín, F.; Hernández, R. y Moreno, J. (eds.). Op. cit., pp. 211-246.

67. Vid. Moreno LÁzARO, J. "Los inicios de la producción fabril de harina en España (17701800)». Revista de Historia Industrial, 1992, 2, pp. 181-187.

68. Cfr. Nieto, J. A. y Zofio, J. C. "Los gremios de Madrid durante la Edad Moderna: una revisión». Áreas. Revista Internacional de Ciencias Sociales, 2015, 35, pp. 47-61.

69. Vid. Ringrose, D. R. Madrid y la economía española, 1560-1850. Ciudad, Corte y País en el Antiguo Régimen. Madrid: Alianza Editorial, 1985. 
industria doméstica con vistas a aprovechar la subcontratación procedente de las fábricas concentradas. La relación de concesión de patentes por parte de la Matritense remite a un horizonte limitado a reforzar el empirismo tradicional, no a sustituirlo. Otros centros a cargo de pensionados e «ingenieros» (Betancourt, López de Peñalver), y que podían haber liderado la aclimatación de tecnologías industriales - la proyectada Academia de Ciencias o el Gabinete de Máquinas (1792)-, carecieron de medios, de apoyo oficial y de continuidad.

\subsubsection{El "desierto manufacturero» extremeño}

Constituyó el correlato de una economía en que la débil colonización del territorio, la concentración de la propiedad y el predominio de los usos extensivos del suelo anticipaban un escenario de baja productividad agraria y de escasas expectativas fabriles ${ }^{70}$ ya previsto por quienes bien conocían aquellas tierras:

Montes de encinas y dehesas son la causa de la infelicidad de esta tierra porque pudiera dársele al territorio cultivo más útil y conducente a la población ${ }^{71}$.

Si, en 1732, el regidor perpetuo de Badajoz Zabala y Auñón se lamentaba de la excesiva carga fiscal sostenida por los vecinos más pobres, en el Memorial ajustado de 1771 se señalaba que «el común del vecindario está poco menos que adscrito a la gleba de los hacendados». Testimonios que se reiterarán hasta finales de siglo. En 1791, Meléndez Valdés recibía la creación de la Audiencia con la esperanza de que supusiese una inflexión en la economía regional. Sin embargo, el discurso de Arias Mon con ocasión de su apertura no dejará lugar a dudas: poco cabría esperar, afirmaba, de un "país dividido entre infelices jornaleros y hacendados poderosos". Un año después, en el Informe sobre el estado de la agricultura extremeña en el que comentaba el Interrogatorio de 1791, señalaba la inutilidad de alumbrar proyectos de cambio: en este país «todo se malogra».

Ante tal panorama, el papel de las Sociedades Económicas de Plasencia y Trujillo, animadas por el estamento parroquial, apenas superó la difusión de cartillas rústicas. Los núcleos textiles habían decaído (Tornavacas, Plasencia, Cáceres) o, ante la escasez de ganados estantes y la reserva de lanas finas para las Reales Fábricas, se hallaban en franco retroceso (Torremocha, Castajeda, Hervás). La fábrica de seda de Zarza la Mayor (1746), dependiente de la Real Compañía de Comercio

70. Vid. Llopis AgELÁN, E. «El agro extremeño en el Setecientos: crecimiento demográfico, invasión mesteña y conflictos sociales». En Estructuras agrarias y reformismo ilustrado en la España del siglo XVIII. Madrid: Ministerio de Agricultura, 1989, pp. 267-290, y LlOPIS AgELÁN, E. «La formación del desierto manufacturero extremeño: el declive de la pañería tradicional al final del Antiguo Régimen». Revista de Historia Industrial, 1993, 3, pp. 41-64.

71. Cfr. PONZ, A. "Carta VII (1778)». En Viaje de España (1772-1794). Madrid: Aguilar, 1947, tomo VII, p. 637. 
y Fábricas de Extremadura, pese al privilegio exclusivo para el comercio con Portugal, apenas superará una década de actividad ${ }^{72}$.

\subsection{De la excepción catalana a la "periferización» aragonesa}

La Nueva Planta borbónica no impidió que desde 1714 Cataluña conservase intacta su vitalidad económica ${ }^{73}$. La supresión de las aduanas interiores entre Aragón y Castilla facilitó la "conquista pacífica» del mercado español por la diáspora comercial catalana, a la vez que fortalecía especializaciones productivas no agrarias en las comarcas interiores del Anoia a la Garrotxa, peor dotadas de tierras aptas para el cultivo. La posterior apertura del mercado colonial estimuló la construcción naval, los seguros y los fletes. En 1780, la Junta de Comercio daba cuenta de que

Las fábricas de indianas componen la mayor parte del comercio activo de este Principado. El dinero, que en otras provincias está como estancado en pocas manos, en Cataluña es un humor que circula y se extiende por todos los miembros... ${ }^{74}$.

En un entorno económico en que industria popular y gremios convivían en armonía con las fábricas de indianas, nada tuvo de extraño que el Ayuntamiento de Barcelona se desmarcase de la estrategia de crecimiento impulsada desde el Consejo de Castilla por Campomanes ${ }^{75}$. Y es que, a diferencia de los casos gallego y vasco, en Cataluña, las propuestas industrialistas no circulaban de arriba abajo: las instituciones catalanas actuaron como caja de resonancia de los intereses fabriles y empresariales.

El textil lo ejemplifica como ninguna otra manufactura. Y es que, "mejor aún que fabricante, el catalán ha sido comerciante», y en la conquista del mercado, los fabricantes catalanes aprendieron "a comprimir sus precios mediante la técnica ${ }^{76}$. Pero los fabricantes-comerciantes no estaban solos. La Junta de Comercio (1758) y la Academia de Ciencias y Artes (1764) acabaron por beneficiarse de la descentralización de los estudios científico-técnicos respecto al espacio académico

72. Vid. MELÓN JiméNEZ, M. A. «Un capítulo singular de la historia extremeña: la Real Compañía de Comercio y Fábricas de Extremadura (1746-1756)». Revista de Estudios Extremeños, 1987, vol. 43, 2 , pp. 593-528, y Extremadura en el Antiguo Régimen. Mérida: Editora Regional de Extremadura, 1989.

73. Vid. MARTínez Shaw, C. "La Cataluña del siglo XVIII: bajo el signo de la expansión». En FeRNÁNDEZ DíAZ, R. (ed.). 1985, op. cit., pp. 55-131.

74. Cfr. Junta DE COMERÇ DE BARCELONA. Discurso sobre la agricultura, comercio e industria del Principado de Cataluña (1780). Ed. E. Lluch. Barcelona: Alta Fulla, 1997, pp. 52-53.

75. Vid. Lluch, E. Las Españas vencidas del siglo XVIII. Claroscuros de la Ilustración española. Barcelona: Crítica, 1999, pp. 174-190.

76. Las citas en: NADAL, J. "Cataluña, la fábrica de España». En Moler, tejer, fundir. Estudios de bistoria industrial. Barcelona: Ariel, 1992, p. 117, y VILAR, P. "La Cataluña industrial...». En VILAR, P. et al. (eds.). La industrialización europea. Estadios y tipos. Barcelona: Crítica, 1981, p. 189. 
instaurado desde $1714^{77}$. El "Discurso inaugural» (1764) de la Conferencia FísicoMatemática, a cargo de F. Subirats, no dejaba lugar a dudas acerca del compromiso entre ciencia e industria: tras lamentar el atraso en las «artes», el conferenciante se preguntaba: «QQué le suena mejor al Estado, las voces del claustro o el ruido de las máquinas de los artesanos?». Dos casos singulares ilustran lo que se comenta: el de los tintes y blanqueo, y el de mecanización de la hilatura.

Las primeras manufacturas concentradas de indianas adolecían de buenas técnicas de pintado, principal barrera de entrada al sector. Desde 1728, la firma Gloria y C. ${ }^{a}$, y desde 1732 la de A. Serra, hubieron de acudir a técnicos extranjeros. Dado que se trataba de un problema que afectaba a todos los fabricantes -los Fomentí, Canaleta, Canals...-, la Junta de Comercio, a través de escuelas de química, trató de replicar el know-how o "secretos» de la tintura que otorgaba a los técnicos foráneos una posición monopolística ${ }^{78}$. La propia Junta creaba en 1735 la figura del "visitador general de tintes", además de patrocinar publicaciones destinadas a divulgar los nuevos procedimientos de tintado y blanqueo. En 1765, en la barcelonesa Real Conferencia de Física se señalaba que no era su objeto la química médica: "Solo la química económica y la química mecánica son las más útiles y necesarias a nuestras artes y, por lo mismo, solo en esto se debe instruir a los artífices ${ }^{79}$. El proceso culminará en 1805 con la creación de la Escuela de Química y una cátedra de "química aplicada a las artes» cuyo primer titular, F. Carbonell i Bravo, vinculaba su formación a Chaptal y al "círculo de Montpellier».

En el caso de la mecanización de la hilatura y tejido, de nuevo interesa enfatizar los vínculos entre el sector empresarial y las citadas instituciones. Desde 1773, la Junta de Comercio pensionaba y premiaba a quienes difundiesen «inventos industriales» que abaratasen los costes de las manufacturas. Del igual modo, desde la Conferencia de Física se insistía en el carácter aplicado de las enseñanzas de álgebra, química o estática, que debían dirigirse al diseño y aclimatación de "máquinas e instrumentos útiles a las artes» y que mejorasen «el modo de cardar, hilar, tejer, batanar, tundir y peinar» los paños. En la transferencia tecnológica, la Junta, con vistas a reducir costes de transacción, actuará de intermediaria entre los fabricantes catalanes y los técnicos ingleses en las negociaciones sobre acuerdos de explotación de patentes o concesión de privativas de explotación.

Un caso representativo de esta colaboración fue el de la fábrica de hilados de Jacint Ramon, pionero en aplicar en 1804 el vapor al hilado en colaboración

77. Vid. Nieto-Galán, A. y Roca Rosell, A. (coords.). La Reial Acadèmia de Ciències i Arts de Barcelona als segles XVIII $i$ XIX. Història, ciencia $i$ societat. Barcelona: Institut d'Estudis Catalans, 2000.

78. Vid. Thompson, J. Els orígens de la industrialització a Catalunya. El cotó a Barcelona, 1728-1832. Barcelona: Ed. 62, 1994, y BENAul, J. M. «La transferencia de tecnología a la industrialització lanera». En MaluQuer, J. (dir.). Tècnica i tecnología en el desenvolupament de la Catalunya contemporània. Barcelona: Fundación Enciclopedia Catalana, 2000, pp. 192-204.

79. Cfr. García-Doncel, M. «Els quatre enfocaments inicials de l'Academia». En Nieto Galán, A. Op. cit., pp. 92-99. 
con F. Santponç, director de Estática de la Academia de Ciencias Naturales y Artes y, desde 1806, de la Escuela de Mecánica de la Junta de Comercio. Siguiendo las directrices de esta, Santponç dará un marcado carácter utilitario a su magisterio: "No se trata de formar néwtones, sino artistas y fabricantes que puedan discurrir con solidez y fundamento» ${ }^{80}$. En su Noticia de una bomba de fuego (1805), volvía a plantear el mismo espíritu industrialista:

Con los medios de usar la gran potencia de la bomba de fuego, podrá cualquier maquinista aplicarla a infinitos ramos de la industria. Yo espero que la bomba de vapor que presento ha de tener un influjo decisivo a favor de nuestra industria nacional ${ }^{81}$.

Se trataba del mismo espíritu utilitario presente en la obra de F. Salvá y Campillo, coautor con Santponç de una Disertación sobre la explicación y uso de una máquina de vapor para agramar cáñamos y linos (1784), y en cuya Memoria sobre la construcción de instrumentos meteorológicos (1790), al referir «la íntima conexión que hay entre las ciencias más útiles y las artes fabriles», escribía:

Solamente en aquellos países en que los artífices se dedican a la construcción de instrumentos científicos, pueden hacer progresos rápidos las ciencias experimentales. Los sabios, sin el auxilio de las artes, se verán atrasados diariamente ${ }^{82}$.

Desde un escenario próximo pero bien distinto, Ignacio de Asso lamentaba que en Aragón nunca hubiesen «estado las fábricas tan decaídas como en los tiempos actuales» ${ }^{83}$. Y es que, pese a su vigor, poco pudieron hacer las luces aragonesas por corregir la deriva económica del Reino hacia una especialización productiva primario-exportadora (aceite, cereales, vino, lino) a la que se subordinará buena parte de su tejido manufacturero ${ }^{84}$. La obra de Arteta expresa meridianamente la conciencia de la "periferización" aragonesa respecto a Cataluña ${ }^{85}$.

80. Cfr. Nieto-Galán, A. La seducción de las máquinas: vapores, submarinos, inventores. Madrid: Nívola, 2000, p. 55.

81. Cfr. Agustí Cullel, J. Ciència i técnica a Catalunya en el segle XVIII. La introducció de la máquina de vapor. Barcelona: Institut d'Estudis Catalans, 1983, pp. 141-183.

82. Cfr. Riera i TuèBols, S. Ciència i tècnica a la Ilustració: Francesc Salvá i Campillo (17511828). Barcelona, 1985, pp. 229-230.

83. Cfr. Asso, Ignacio de. Historia de la economía política de Aragón (1798). Zaragoza: Guara editorial, 1983, p. 123.

84. Para una visión de conjunto: Fornies Casals, J. F. La Real Sociedad Aragonesa de Amigos del País en el período de la Ilustración (1768-1808): sus relaciones con el artesanado y la industria. Madrid, 1978.

85. ARTETA De MONTESEguro, A. Discurso instructivo sobre las ventajas que puede conseguir la industria de Aragón con la nueva ampliación de puertos concedida por S. M. para el comercio de América en que se proponen los géneros y frutos de este Reino más útiles a este fin, y los medios de extraerlos y negociarlos con mayor economía y beneficio (1783). Ed. A. Pérez Sarrión. Zaragoza: Diputación General de Aragón, 1985; Fernández Clemente, E. y Pérez SARrión, G. "El siglo XviII en Aragón: una economía dependiente». En FERnÁNDEZ DíAz (ed.). España en el siglo XVIII, 1985, op. cit., pp. 565-629; 
Las compañías catalanas controlaban la comercialización del trigo, de la madera y del vino, además de hallarse presentes en los sectores manufactureros más rentables (madera, tenerías). Pese a las ventajas suscitadas por el Canal Imperial, por los proyectos de navegación del Ebro y por la liberalización del comercio colonial, "Aragón no disfrutará de ellas» pues, señalaba Arteta, carecía de comerciantes con capitales, de ahí la acusada presencia de iniciativas foráneas en el comercio y manufacturas, caso del cristal o del acero de Utrillas. De ahí también que la Aragonesa centrase sus esfuerzos en el sector textil: difusión de las obras de Mercandier, de F. Salvá y F. Santpontç sobre una nueva agramadora; de Cistué sobre el blanqueo de lienzos; de Lapayese sobre el hilado de la seda; de Berthollet sobre tintes... Además, trató de establecer contacto con la Compañía de Hilados de Barcelona con vistas a la posible creación de hilanderías de algodón. Fuera del textil, no faltaron memorias dirigidas a mejorar los trabajos del hierro (Albarracín, Ojos Negros, Bielsa) o difundir el uso del carbón mineral ${ }^{86}$.

2.6. Andalucía: «Muchos comerciantes acaudalados han cobrado amor a la agricultura»

Esta frase, recogida de una memoria del Consulado de Sevilla fechada en 1788, ratificaba las apreciaciones que ya en el siglo XVI formulará Tomás de Mercado sobre la huida de capitales hacia el agro. En 1778, Jovellanos, instalado en Sevilla, al redactar una propuesta sobre la fundación en Cádiz de una Sociedad Económica, recomendaba centrar la atención en el ámbito de la navegación y de las pesquerías ${ }^{87}$ pese a la fuerte competencia de las compañías de "fomentadores» catalanes establecidos en Huelva. Y justificaba así tal prioridad:

No puede prosperar un pueblo donde abunda tanto el dinero y donde el alto precio de las cosas necesarias para la vida hacen casi imposible la subsistencia de las fábricas.

En Málaga, los intereses del "gran comercio» -navieros y exportadores de vino, seda y pasas-, además de representados en el Montepío de Viñeros y en el Consulado, fueron mayoritarios en la Sociedad Económica ${ }^{88}$. Lo que Tinoco Rubiales bautizó como «la rentabilidad del absentismo industrial» andaluz resistía el

Zorraquino, J. I. «Las colonias mercantiles extranjeras en Aragón». En Villar García, M. B. y PezZi, P. (eds.). Los extranjeros en la España moderna. Málaga, 2003, I, pp. 365-377.

86. En 1785, Diego de Torre, en una memoria titulada Introducción del carbón de piedra para usos industriales en Zaragoza, proponía abrir un camino que conectase la capital con las minas turolenses de Utrillas.

87. Vid. textos de la sección «Sevilla: Real Audiencia y Sociedad Patriótica de Amigos del País (1767-1778)». En Obras completas. X. Escritos económicos. Op. cit., pp. 397-473.

88. Vid. Villas Tinoco, S. «Málaga, el mundo del trabajo y la Sociedad Económica de Amigos del País en el siglo XVIII». Jabega, 1982, 43, pp. 34-43. 
paso del tiempo ${ }^{89}$. Desde la primera mitad del siglo, los ilustrados andaluces -de la Antorcha (1703) de G. Naranjo al Manifiesto (1730) del marqués de Villadariashabían apostado por las compañías privilegiadas como una vía de industrialización en la que el capital público suplía la abstinencia del privado. Sus fracasos sucesivos explican en parte el protagonismo extranjero en las iniciativas industriales, desde el curtido a la siderometalurgia pasando por el textil ${ }^{10}$.

La respuesta del Consulado de Cádiz a la Encuesta de 1787 con la que se trataba de valorar los efectos del reglamento de 1778 sobre la liberalización del comercio a Indias refería el fracaso de los distintos proyectos algodoneros debido a la saturación del mercado. A la vista de los resultados cosechados en el ámbito manufacturero, no resulta extraño que la mayor parte de las recomendaciones económicas ofrecidas desde las distintas Sociedades Económicas insistiesen en propuestas de carácter agrarista o agronómico ${ }^{91}$. En el caso de la industria, las Sociedades seguirán las directrices campomanistas: fomento de la industria rural doméstica, reforma gremial -caso de las Reflexiones sobre las artes mecánicas (1776) de Francisco de Bruna- o enseñanza profesional a través de la red de hospicios y de "escuelas-fábrica» de lencería, hilazas, cintería y medias. Es decir, en ambos casos, considerados los intereses económicos establecidos, la industria no podía dejar de entenderse más que como un sector refugio para la población rural o urbana subempleada, y no como una actividad con capacidad para generar una vía de crecimiento alternativa a la comercial o agraria.

2.7. El comercio antes que la industria: Rioja, Valencia, Murcia y las economías insulares

Las ganancias del comercio son mucho mayores que las que prometen las fábricas. Los comerciantes, no destinan regularmente sus fondos al fomento de las fábricas. No esperemos el restablecimiento de las fábricas de la sola abundancia de brazos ni

89. "Ya como exportadores de frutos regionales, ya en los envíos de manufacturas, tanto los privilegiados como los miembros de la burguesía dieciochesca de Cádiz y Sevilla, aceptaron de buen grado una dependencia industrial de la que, por lo demás, obtenían beneficios sin incurrir en los riesgos inherentes a la producción": $c f r$. Tinoco RuBiales, S. "Capital y crédito en la Baja Andalucía». En Fontana, J. (ed.). La economía española al final del Antiguo Régimen. Comercio y colonias. Madrid: Alianza/Banco de España, 1982, pp. 299-331.

90. Una síntesis en BERNAL, A.-M. "La industrialización de Andalucía antes de la revolución industrial». En GonZález de Molina, M. y Parejo Barranco, A. (eds.). La Historia de Andalucía a debate (III): Industrialización y desindustrialización en Andalucía. Granada: Diputación, 2004, pp. 77-103.

91. Vid. ANES, G. "Pensamiento ilustrado sobre los problemas agrarios de Andalucía: Francisco de Bruna y Ahumada». En Ruiz, G. (coord.). Andalucía en el pensamiento económico. Málaga: Aragunal, 1987; MarTín Rodríguez, M. Historia del pensamiento económico en Andalucía. Granada: Comares, 2012, pp. 131-175. 
del celo de algunos particulares, ni aún, me atrevo a decirlo, de los esfuerzos de la autoridad y del patriotismo (Nava y Grimón) ${ }^{92}$.

\subsubsection{La Rioja: "Prosperarás extrayendo»}

Así rezaba el lema que jalonaba el escudo de la Sociedad Económica de la Rioja Castellana, constituida en 1792 a partir de la "congregación» de las 52 localidades del Valle con intereses en el sector vinícola. El núcleo fundacional de la misma se remonta a la Junta General de Cosecheros, creada en 1729 con el fin de regular el comercio del vino y de asegurar retornos a los arrieros que se dirigían a los puertos del Cantábrico ${ }^{93}$. La carencia de técnicas de conservación y envejecimiento de los caldos imponía una comercialización y consumo rápidos. De ahí que la Sociedad, actuando en representación de los cosecheros-propietarios de bodegas, centrase su actuación en la demanda de infraestructuras a través del Ebro, del Iregua y del camino Logroño-Santander. En los pueblos de la Sierra, la ganadería trashumante, el comercio de lanas y la manufactura textil doméstica en el entorno de las villas cameranas compensaban la deficiente aptitud agraria de las tierras. La Real Fábrica de Ezcaray -nacida como empresa mixta en 1751 y desde 1781 administrada por los Cinco Gremios Mayores de Madrid- contribuyó parcialmente a apuntalar aquella orientación manufacturera ${ }^{94}$.

\subsubsection{Valencia y Murcia: el fracaso de sedería}

En Valencia, la Sociedad Económica (1785) actuó de la mano de la Junta Particular de Comercio en defensa de los intereses de los comerciantes-fabricantes sederos del Arte Mayor, centrados en la protección y reserva del mercado más que en la libertad de industria o en la industria popular. La labor publicística de la Sociedad canalizó sus esfuerzos hacia la divulgación de los tratados de Valcárcel, Lapayese y Ortells sobre el "método de Vauçanson» con vistas a mejorar la productividad y costes de los procesos de hilado, torcido y devanado de la seda. El Tratado del arte de hilar, devanar, doblar y torcer la seda, según el método de Mr. Vaucanson (1779), de Lapayese, conocerá tres ediciones. La de 1794, iba precedida de un discurso en que manifestaba su desconfianza hacia la Real Orden de 22 de octubre de 1787 estableciendo la libertad de cosecheros y fabricantes. El hilado, señalaba Lapayese, "no podía abandonarse a la industria popular y al

92. Cfr. NAVA GRIMÓN, A. Escritos económicos (1784-1792): Canarias: Economía e Ilustración. Edición de A. M. Bernal y A. M. Macías. Universidad de La Laguna, 1988.

93. Viguera Ruiz, R. "La Real Sociedad Económica de la Rioja Castellana y su apuesta por el progreso». Berceo, 2003, 152, pp. 79-122.

94. Vid. MORENO FERNÁNDEZ, J. R. «Serranos hacedores de paños: pluriactividad y protoindustria en la Montaña riojana c. 1750)». Revista de Historia Industrial, 2004, 25, pp. 11-46. 
arbitrio de cada cosechero", pues, sin reglamentos, "la libertad en el torcido sería el libertinaje», del mismo modo que «la libertad de variar anchos, pesos o máquinas, acabaría en fraude al consumidor ${ }^{95}$. Un miembro de la Sociedad Económica, G. Merelo y Sayró, presentaba en 1827 una memoria sobre la decadencia de las fábricas de seda en la que achacaba su fracaso tanto a las resistencias gremiales al uso del torno como a los intereses contrapuestos de labradores-cosecheros y comerciantes-fabricantes ${ }^{96}$. A diferencia del modelo lionés o lombardo, el de la sedería valenciana, con el beneplácito de la Junta de Comercio, limitó su alcance a la obtención de seda, no a su transformación industrial; se trató más de un sector agrario que fabril. De hecho, los principales industriales sederos acabaron enterrando sus capitales en el ennoblecimiento y la adquisición de tierras ${ }^{97}$.

Aunque la seda centró el interés de la Sociedad, no faltaron propuestas dirigidas a la mejora de la agricultura -plantíos de olivo (T. Domingo Otero), tratamiento y aprovechamiento de humedales (E. Chaix) o aceite de cacahuete (Tabares de Ulloa)-, al fomento de los canales -memoria de J. M. Lacroix y Vidal sobre un canal de navegación entre Valencia y El Grao-, a la difusión del carbón de piedra ${ }^{98}$, además de elaborar informes sobre las producciones y fábricas de la región (jabón, lino, cáñamo, cerámica, papel) -caso de las Noticias (1793) de Tomás Ricord-.

Murcia ofrece un buen ejemplo del dominio de los intereses de las casas comerciales extranjeras y de sus comisionistas locales en la comercialización de materias primas textiles (seda, lana, esparto) y químicas (barrilla) y en la introducción de manufacturas extranjeras ${ }^{99}$. Al margen del arsenal de Cartagena y de la Real Fábrica de pólvora, la manufactura se limitaba a los sectores agremiados urbanos y a la industria doméstica. La Sociedad Económica murciana, como en el caso de Valencia, limitó su actividad a la difusión de memorias sobre la morera o a las traducciones agronómicas, además de a las funciones asistenciales, muy alejadas en su alcance del proyecto de las Fundaciones Pías de Belluga ${ }^{100}$.

95. Vid. Cervera Ferri, P. El pensamiento económico de la Ilustración valenciana. Valencia: Generalitat, 2002, pp. 425-453.

96. Vid. SARASÚA, C. "Innovaciones técnicas para abaratar los costes del trabajo en la España preindustrial. El programa ilustrado para la industria sedera». En COMÍn, F.; HernándEZ, R. y MORENO, J. (eds.). Op. cit., pp. 189-210.

97. Sobre ambas cuestiones: LLUCH, E. «Pensamiento económico e industrialización sedera en Valencia». En Siete temas sobre historia económica contemporánea del País Valenciano. Universidad de Valencia, 1974, pp. 57-94, y RuIz TORRES, P. «El País Valenciano en el siglo XVIII: la transformación de una sociedad agraria en la época del absolutismo». En FERnÁNDEZ Díaz (ed.). 1985, op. cit., pp. 132-248.

98. Caso de las memorias de J. M. Lacroix y de J. Sánchez Cisneros: vid. López PIÑERo, J. M. y Navarro Brotons, V. La actividad científica valenciana de la Ilustración. Valencia: Diputación, 1988.

99. Vid. PÉrez PicAzo, M. ${ }^{a}$ T. y Lemeunier, G. El proceso de modernización de la región murciana, siglos XVI-XIX. Murcia: Editora Regional, 1984.

100. Vid. VelázQuez GonZÁlez, M. «Las primeras gestiones de la Real Sociedad Económica de Murcia en aras de la regeneración económica del Reino”. Contrastes. Revista de Historia Moderna, 1986, vol. 2, pp. 141-156. 


\subsubsection{Las economías insulares}

La Sociedad Económica mallorquina (1778) integró en su seno a la nobleza insular y a los grandes propietarios de latifundios del olivar y el cereal, antes agrupados en la Cofradía de San Jorge. En 1783, el oidor de la Real Audiencia y segundo director de aquella, J. Antonio Mon y Velarde, hacía un llamamiento a nobles y hacendados para colaborar en un proyecto que cifraba sus objetivos en la preservación de la armonía social. La Idea universal (1784) de la Sociedad seguía estrictamente las líneas de actuación marcadas por Campomanes. De las Memorias de 1784, además de las 6 dedicadas a temas agrarios -desecación de marjales, fomento del cultivo forestal (algarrobo, olivo)-, destacan por su solidez doctrinal y contenido las 3 dedicadas al comercio. Se centraban en demandar un modelo comercial similar al anglo-holandés: el buen comercio, se señalaba, «busca países en donde halla libertad constitucional o no se mezcle el gobierno en sus asuntos sino para protegerlo y nunca para dirigirlo». Además de solicitar la libre exportación de materias primas, se aludía a la debilidad de la flota mercante insular, incapaz de competir en fletes con la catalana, y se demandaba el apoyo público a ciertas manufacturas (aceite, papel, vidrio, salazones) que podrían incorporarse al comercio exterior de la isla ${ }^{101}$.

En el archipiélago canario operaron tres sociedades económicas: las de Gran Canaria (1776), La Palma (1776) y La Laguna (1777). Como telón de fondo de sus actividades se descubren los riesgos asociados a una economía de enclave dependiente de los servicios marítimos prestados al comercio internacional ${ }^{102}$. El primero de tales riesgos se asoció al empeoramiento de los términos de intercambio para su principal exportación, los vinos de malvasía -hecho agravado por el desvío de las importaciones inglesas hacia Portugal a raíz del tratado de Methuen (1703)-. A partir de tal circunstancia, las tres Sociedades trataron de fomentar cultivos de exportación que se apoyasen en las ventajas climáticas de las islas, hecho al que respondió la creación del Jardín Botánico de la Orotava (1787). Las Memorias patrióticas de A. de Nava Grimón, marqués de Villanueva del Prado y director de la Sociedad de La Laguna, son fiel reflejo de los problemas referidos. Las memorias sobre comercio exterior analizaban los efectos perturbadores sobre la economía isleña de los decretos de libre comercio que abrían el mercado colonial a otras plazas peninsulares, lo que daría lugar a amplios debates entre los hacendados y comerciantes locales. Las relativas a la fuerte corriente emigratoria, le sirven para

101. Vid. Moll Blanes, I. «La política agraria de la Sociedad Mallorquina de Amigos del País (1778-1803)». Boletín de la Cámara Oficial de Comercio, Industria y Navegación. Palma de Mallorca 1973, pp. 52-53; Moll Blanes, I. y Suau Puig, J. "Memoria explicativa del estado de las islas de Mallorca en el siglo XVIII. En FERnÁNDEZ DíaZ (ed.). Op. cit., pp. 249-288.

102. Vid. MACÍAS, A. M. (1985). "Canarias en el siglo XVIII: una sociedad en crisis». En FERNÁNDEZ DíAz (ed.). Op. cit., pp. 413-433, y "Canarias: una economía insular y atlántica». En GERMán, L. et. al. (eds.). Op. cit., pp. 476-506. 
denunciar la falta de empleos alternativos al agrario y la ausencia de perspectivas industriales, tal como explica la cita que abría este apartado.

\section{CONClusiones}

Me atrevería a concluir que si no hubo crecimiento industrial no fue «a causa" del gobierno, y que el crecimiento producido no fue "a pesar" del gobierno, sino que se vio favorecido por el conjunto de su acción (V. Llombart, 1994) $)^{103}$.

Este texto de Llombart, redactado a propósito del debate sobre la eficacia de la acción gubernamental en materia de política industrial, viene a cuento de lo hasta aquí analizado. El discurso industrialista salido del ámbito de la economía política tuvo una débil capacidad de influencia sobre los policy makers, limitada a aquellos casos en que los propios economistas llegaron a compartir labores de gobierno. Ciñéndonos a la manufactura, el caso de Campomanes resulta elocuente: su presencia en el Consejo de Castilla permitirá desarrollar medidas para la dignificación de los oficios viles, la liberalización del trabajo e industria, la revisión de los privilegios gremiales y de las Compañías de Comercio y fábricas, la crítica a las manufacturas estatales o la apertura del mercado colonial, entre otras muchas. Ahora bien, que aquel discurso llegase a plasmarse en políticas industriales no garantizaba su eficacia. La acción pública requería de factores de acompañamiento o facilitadores que solían brillar por su ausencia. Baja productividad agraria y escaso desarrollo urbano, débil integración del mercado y restricciones institucionales condicionaron las respuestas y organización empresariales. El recurso a las sociedades familiares, a la descentralización del negocio, a la diversificación inversora y al capital comercial como proveedor de crédito y circulante fue la forma de minimizar riesgos. La oferta de privilegios por parte de la Corona irá en la misma dirección: reducir barreras de entrada e incertidumbres. Por otro lado, y aun contando con la iniciativa empresarial o con capitales procedentes del comercio, fueron contados los sectores -algodón, harinería, papel...- que además de superar las dificultades finiseculares aportaron un modelo técnico y organizativo viable.

Entre 1775 y 1808 se crearon 97 Sociedades Económicas -32 de ellas en Andalucía, 20 en Castilla-León y 12 en Castilla-La Mancha-. A la hora de valorar sus realizaciones, la historiografía no ha dejado de llamar la atención sobre el hecho de su ausencia en algunas de las ciudades y puertos que contaron con mayor actividad mercantil y manufacturera -Bilbao, Barcelona, Cádiz, La Coruña-. Ni la desproporción entre objetivos, medios y resultados propuestos en sus estatutos, ni su composición social, permitían presagiar que adquiriesen protagonismo en

103. Cfr. Llombart, V. (1994). Op. cit., p. 32. 
el fomento fabril más allá de mejorar el papel negociador y la intermediación de los empresarios ante la Corona. Casi de forma generalizada, su papel se agotó en las funciones asistenciales y educativas con las que venían a paliar parcialmente la escasa dotación de bienes públicos. Sus actuaciones económicas se centraron en tres ámbitos. En el agrario, trataron de mejorar la oferta de conocimientos técnicos y agronómicos mediante traducciones y difusión de cartillas rústicas. En el manufacturero, la convocatoria anual de premios recaía inevitablemente en actividades, técnicas e instrumentos de trabajo propias del ámbito gremial. El mayor activo de las Económicas residió en su esfuerzo por mejorar la formación económica o doctrinal de sus miembros -cátedras de economía, traducciones- y en su contribución a elevar el nivel del debate sobre temas centrales de la economía española -desamortización, minería, comercio exterior, aranceles, etc.-.

Consulados, juntas de comercio, audiencias, academias de agricultura y artes, seminarios e instituciones forales vieron condicionada su actuación, bien por los intereses sociales que representaban -reflejo del tejido económico en que se incardinaban-, bien por las directrices gubernamentales. En el caso de los consulados y juntas de comercio, los casos descritos prueban la frecuente contraposición de objetivos e intereses entre comerciantes y fabricantes. Por todo ello, el caso catalán podría parecer excepcional, pero se trata solo de una apariencia: como señalaron P. Vilar y J. Nadal, una larga y previa trayectoria económica explica que, en aquella región, fabricante y comerciante -a veces una misma persona- fuesen de la mano en la conquista del mercado interior.

\section{FUENTES Y BIBLIOGRAFÍAS}

\subsection{Fuentes primarias}

Alcalá Galiano, Vicente. Sobre la Economía política y los tributos (1781). Ed. de J. M. Valles Garrido. Segovia, 1992.

ARRIQUiBAR, N. Recreación política (1779). Ed. de J. Astigarraga y J. M. Barrenechea. Vitoria, 1987.

Arteta de Monteseguro, A. Discurso instructivo sobre las ventajas que puede conseguir la industria de Aragón con la nueva ampliación de puertos concedida por S. M. para el comercio de América en que se proponen los géneros y frutos de este Reino más útiles a este fin, y los medios de extraerlos y negociarlos con mayor economía y beneficio (1783). Ed. de G. Pérez Sarrión. Zaragoza: Diputación General de Aragón, 1985.

Asso, Ignacio de. Historia de la economía política de Aragón (1798). Zaragoza: Guara, 1983. CABARRús, F. Cartas (1808). Ed. de J. M. Maravall. Madrid: Castellote, 1972.

CAMPOMANES, P. R. conde de. Reflexiones sobre el comercio español a Indias (1762). Ed. de V. Llombart. Madrid: Instituto de Estudios Fiscales, 1988.

Campomanes, P. R. conde de. Discurso sobre el fomento de la industria popular. Imp. A de Sancha. Madrid, 1774.

CAmpomanes, P. R., conde de. Apéndice a la educación popular, III (1776). Ed. de V. Llombart. Oviedo: Instituto Feijoo de Estudios del Siglo XVIII, 2009. 
JOAQUÍN OCAMPO SUÁREZ-VALDÉS Y PATRICIA SUÁREZ CANO

Canga Argúelles, J. Diccionario de Hacienda. Madrid, 1833.

Capmany, A. de. Discurso económico-político en defensa del trabajo mecánico de los menestrales y de la influencia de los gremios en las costumbres populares, conservación de las artes y bonor de los artesanos. Barcelona.

DÁmASO GENERÉs, M. Reflexiones políticas y económicas sobre la población, agricultura, artes, fábricas y comercio del Reyno de Aragón (1793). Ed. de E. Lluch y A. Sánchez Hormigo. Zaragoza, 1996.

ForOnDA, V. de. Cartas sobre los asuntos más exquisitos de la Economía política (17881791). Ed. de J. M. Barrenechea. Vitoria, 1994.

GánDara, M. A. de la. Apuntes sobre el bien y el mal de España (1759). Ed. de J. Macías Delgado. Madrid: I. de Estudios Fiscales, 1988.

Heros, J. A. Discursos sobre el comercio (1775). Edición de J. M. Barrenechea. Madrid: Espasa-Calpe, 1989.

Jovellanos, M. G. de. «Informe sobre el libre ejercicio de las artes» (1785), "Carta sobre la industria de Asturias» (1795) e "Introducción a un discurso sobre la Economía civil» (1796). En Llombart, V. y Ocampo, J. (eds.). Obras completas. X. Escritos económicos. Oviedo: Instituto Feijoo de Estudios del Siglo XVIII, 2008.

Junta DE COMERÇ DE BARCelona. Discurso sobre la agricultura, comercio e industria del Principado de Cataluña (1780). Ed. de Ernest Lluch. Barcelona: Alta Fulla, 1997.

Labrada, Lucas. Descripción económica del Reino de Galicia (1804). Ed. de F. Río Barja. Vigo: Galaxia, 1971.

MANSO, J. Estado de las fábricas, comercio, industria y agricultura en las montañas de Santander (1798). Ed. de T. Martínez Vara. Santander: Estudio, 1979.

MONCADA, S. Restauración política de España (1619). Ed. de J. Vilar. Madrid: Instituto de Estudios Fiscales, 1974.

Munibe, J. M., conde de Peñaflorida. Discursos inéditos (1779). Ed. de J. Astigarraga. Vitoria: Ararteko, 2002.

Nava Grimón, A. Escritos económicos (1784-1792). Ed. de A. M. Bernal y A. M. Macías. La Laguna: Universidad de La Laguna, 1988.

Normante y Carcavila, C. Proposiciones de economía civil y de comercio (1785). Ed. de A. Peiró Arroyo. Zaragoza, 1984.

Polo y Catalina, J. Informe sobre las fábricas e industria de España (1804) y otros escritos. Ed. de A. Sánchez Hormigo. Zaragoza: Prensas Universitarias de Zaragoza, 2005.

Ponz, A. Viaje de España (1772-1794). Madrid: Aguilar, 1947.

Real Sociedad Vascongada de los Amigos del País. Extractos aprobados por S. M. para el gobierno de la Real Sociedad Bascongada de los Amigos del País (1764-1775). San Sebastián: Sociedad Guipuzcoana de Ediciones, 1985.

Romá I Rosell, F. Disertación histórico-político-legal por los Colegios y Gremios de la ciudad de Barcelona y sus privativas. Barcelona, 1766.

Romá I Rosell, F. Las señales de la felicidad de España y medios de hacerlas eficaces (1768). Ed. de E. Lluch, Barcelona, 1989.

Tricio, A. D. de. La Montaña en 1784. Informe a la Junta de Comercio y Moneda. Ed. de M. A. Sánchez Gómez. Santander: Universidad de Cantabria, 2007.

UzTÁriz, G. Theórica y práctica de comercio y de marina (1724). Ed. de G. Franco. Madrid: Fondo de Cultura Económica, 1968. 
VIDAL y CABASÉS, F. Reflexiones económicas sobre ciertos arbitrios de propagar la agricultura, artes, fábricas y comercio, dirigidas a los encargados y amantes del bien público. Madrid: Imp. de A. Sancha, 1781.

Ward, B. Proyecto económico en que se proponen varias providencias dirigidas a promover los intereses de España con los medios y fondos necesarios para su planificación (1779). Ed. de J. L. Castellan. Madrid: Instituto de Estudios Fiscales, 1982.

\subsection{Bibliografía}

Agustí Cullel, J. Ciència i técnica a Catalunya en el segle XVIII. La introducció de la máquina de vapor. Barcelona: Institut d'Estudis Catalans, 1983, pp. 141-183.

Alonso Álvarez, L. Industrialización y conflictos sociales en la Galicia del Antiguo Régimen, 1750-1830. Madrid: Akal, 1977.

ANES, G. "Pensamiento ilustrado sobre los problemas agrarios de Andalucía: Francisco de Bruna y Ahumada». En RuIz, G. (coord.). Andalucía en el pensamiento económico. Málaga: Argunal, 1987.

ANGUlo Morales, A. «Bilbao, Madrid, Londres: Ganaderos, comerciantes y cambistas vascos en los mercados financieros y laneros del Atlántico». En OcAmpo, J. (ed.). Empresas y empresarios en el norte de España (siglo XVIII). Gijón: Trea, 2012, pp. 183-210.

AstigarRaga, J. "La Sociedad Económica de Navarra en la segunda mitad del siglo XVIII». Gerónimo Uztáriz, 1992, 6-7, pp. 25-78.

AstigarRaga, J. Los ilustrados vascos: ideas, instituciones y reformas económicas en España. Barcelona: Crítica, 2003.

Benaul, J. M. «La transferencia de tecnología a la industrialització lanera». En MALuQuer, J. (dir.). Tècnica i tecnología en el desenvolupament de la Catalunya contemporània. Barcelona, 2000, pp. 192-204.

Benaul, J. M. y SÁncheZ, A. «El legado industrial del Antiguo Régimen». En Llopis, E. (ed.). El legado económico del Antiguo Régimen. Barcelona: Crítica, 2004, pp. 187-228.

BERG, M. "Political economy and the principles of manufacture (1700-1800)». En HudSON, P. (ed.). Manufactures, town and country before the factory. Cambridge, 1983, pp. 33-61.

BERNAL, A. M. «La industrialización de Andalucía antes de la revolución industrial». En GoNzÁlez de Molina, M. y Parejo Barranco, A. (eds.). La Historia de Andalucía a debate (III): Industrialización y desindustrialización en Andalucía. Diputación de Granada, 2004, pp. 77-103.

BREWER, A. «The concept of growth in Eighteenh-Century Economics». History of Political Economics, 1995, vol. 27, 4, pp. 609-638.

Carmona, J. El atraso industrial de Galicia, Auge y liquidación de las manufacturas textiles (1750-1900). Barcelona: Ariel, 1990.

CARRIÓN ARREgUI, I. La siderurgia guipuzcoana en el siglo XVIII. Universidad del País Vasco, 1991.

CERVERA FerRI, P. El pensamiento económico de la Ilustración valenciana. Valencia: Generalitat de Valencia, 2002.

Coll MarTín, S. "La minería del carbón en España a finales del Antiguo Régimen (17701835)». En Tedde, P. (ed.). La economía española al final del Antiguo Régimen. II. Manufacturas. Madrid: Banco de España, 1982, pp. 229-236. 
Dobado, R. y López, S. "Castilla-La Mancha: del vasto territorio y la escasez de hombres». En Germán, L. (ed.). Historia económica regional de España. Barcelona: Crítica, 2001, pp. 238-270.

Dopico, F. A Ilustración e a sociedade galega: A visón dos ilustrados. Vigo: Galaxia, 1978.

Dopico, F. «El proyecto económico de los ilustrados gallegos». En FuENTES QuintanA, E. (dir.). Economía y economistas españoles. 3. La Ilustración. Barcelona: Funcas, 2000, pp. 641-676.

Felipe, E. "Científicos de la Francia republicana en el Real Seminario de Vergara (17851815)». En Gárate Ojanguren, M. y Rubio Urquía, G. (coords.). V Seminario de Historia de la Real Sociedad Bascongada de Amigos del País: La Bascongada y Europa. Madrid, 1999, pp. 601-616.

Fernández Clemente, E. y Pérez SARrión, G. «El siglo XVIII en Aragón: una economía dependiente». En FERnández díAz, R. (ed.). España en el siglo XVIII (Homenaje a P. Vilar). Barcelona: Crítica, 1985, pp. 565-629.

FERNÁNDEZ DE PINEDO, E. «Notas al comercio de exportación español en la primera mitad del siglo XIX (1792-1842)». En Doctor Jordi Nadal [homenaje]. La industrialización y el desarrollo económico de España. Universitat de Barcelona, 1999, I, pp. 608-627.

FERNÁNDEZ DURÁN, R. Gerónimo de Uztáriz (1670-1732): Una política económica para Felipe V. Madrid: Minerva, 1999, pp. 121-122.

Fornies Casals, J. F. La Real Sociedad Aragonesa de Amigos del País en el período de la Ilustración (1768-1808): sus relaciones con el artesanado y la industria. Madrid: CECA, 1978.

García Colmenares, P. "De la desindustrialización del sector textil lanero castellano a la creación de pequeños centros industriales: Palencia, 1780-1930». En Yun CaSAlilla, B. (coord.). Estudios sobre capitalismo agrario, crédito e industria en Castilla (siglos XIX y XX). Salamanca: Junta de Castilla y León, 1991, pp. 131-159.

GARCíA SANZ, A. Industria textil tradicional y las reformas de la Ilustración: las transformaciones de la pañería segoviana durante el reinado de Carlos III. En Carlos III y la Ilustración. (2) Economía y Sociedad. Madrid: Ministerio de Cultura, 1989, pp. 363-389.

GARCía SANZ, A. «Empresarios en la España del Antiguo Régimen: ganaderos trashumantes, exportadores de lana y fabricantes de paños». En Comín, F. y MarTín ACEÑA, P. (eds.). La empresa en la historia de España. Madrid: Civitas, 1996, pp. 93-114.

García-DOnCEL, M. «Els quatre enfocaments inicials de l'Academia». En NiETO-Galán, A. y Roca Rosell, A. (coords.). La Reial Acadèmia de Ciències i Arts de Barcelona als segles XVIII $i$ XIX. Història, ciencia i societat. Barcelona: Institut d'Estudis Catalans, 2000, pp. 92-99.

GONZÁlez ENCISO, A. "Empresarios navarros en el siglo XVIII». En OCAMPO, J. (ed.). Empresas y empresarios en el norte de España (siglo XVIII). Gijón: Trea, 2012, pp. 297-331.

Helguera, J. «Las Reales Fábricas». En Comín, F. y Martín Aceña, P. (dirs.). Historia de la empresa pública en España. Madrid: Espasa-Calpe, 1991, pp. 55-88.

Helguera QuiJADA, J. «Un empeño fallido de reindustrialización: las Reales Fábricas del siglo XVIII en Castilla y León». En Comín, F.; Hernández, R. y MORENO, J. (eds.). Instituciones políticas, comportamientos sociales y atraso económico en España, 1500-2000. Salamanca: Ediciones de la Universidad de Salamanca, 2017, pp. 211-246.

HERNÁNDEZ García, R. "La industria textil lanera en Castilla y León en el siglo XIX: la inadaptación a un nuevo modelo empresarial». En Comín, F.; Hernández, R. y Moreno, J. (eds.). Instituciones políticas, comportamientos sociales y atraso económico en España, 1500-2000. Salamanca: Ediciones de la Universidad de Salamanca, 2017, pp. 267-286. 
ImízCOZ, J. M. y GuerRero EleCAlDE, R. «Negocios y clientelismo político: los empresarios norteños en la monarquía borbónica». En OCAMPO, J. (ed.). Empresas y empresarios en el norte de España (siglo XVIII). Gijón: Trea, 2012, pp. 331-362.

LlOMbarT, V. «Estudio preliminar». En LlOMBART, V. (ed.): Campomanes: Reflexiones sobre el comercio español a Indias (1762). Madrid: Instituto de Estudios Fiscales, 1988, pp. 22-41.

Llombart, V. Campomanes, economista y político de Carlos III. Madrid: Alianza, 1992.

LlOMBarT, V. «La política económica de Carlos III: ¿Fiscalismo, cosmética o estímulo al crecimiento?». Revista de Historia Económica, 1994, 1, pp. 11-39.

LLOMBART, V. «Economía política y reforma en la Europa mediterránea del siglo XVIII: una perspectiva española». Mediterráneo Económico, 2006, 9, pp. 95-113.

LLOPIS AGELÁN, E. "El agro extremeño en el Setecientos: crecimiento demográfico, invasión mesteña y conflictos sociales». En Estructuras agrarias y reformismo ilustrado en la España del siglo XVIII. Madrid: Ministerio de Agricultura, 1989, pp. 267-290.

Llopis Agelán, E. «La formación del desierto manufacturero extremeño: el declive de la pañería tradicional al final del Antiguo Régimen”. Revista de Historia Industrial, 1993, 3, pp. 41-64.

Llopis Agelán, E. «El legado económico del Antiguo Régimen desde la óptica regional». En GERMán, L. (ed.). Historia económica regional de España. Barcelona: Crítica, 2001, pp. 507-524.

Llopis Agelán, E. «España, la "revolución de los modernistas" y el legado del Antiguo Régimen». En LLopis, E. (ed.). El legado económico del Antiguo Régimen. Barcelona: Crítica, 2004, pp. 11-76.

LLuCH, E. "Pensamiento económico e industrialización sedera en Valencia». En Lluch, E. (ed.). Siete temas sobre historia económica contemporánea del País Valenciano. Universidad de Valencia, 1974, pp. 57-94.

LluCH, E. Las Españas vencidas del siglo XVIII. Claroscuros de la Ilustración española. Barcelona: Crítica, 1999.

Lluch, E. «El cameralismo en España». En Fuentes QuinTana, E. (dir.). Economía y economistas españoles. 3. La Ilustración. Barcelona: Funcas, 1999, pp. 721-760.

López Piñero, J. M. y NAVARRo BROTONS, V. La actividad científica valenciana de la Ilustración. Diputación de Valencia, 1988.

MaCíAs, A. M. «Canarias en el siglo XVIII: una sociedad en crisis». En Fernández Díaz, R. (ed.). España en el siglo XVIII (Homenaje a P. Vilar). Barcelona: Crítica, 1985, pp. 413-433.

MACíAs, A. M. "Canarias: una economía insular y atlántica». En GERMán, L. et al. (eds.). Historia económica regional de España. Barcelona: Crítica, 2005, pp. 476-506.

Maluquer, J. (dir.). Tècnica $i$ tecnología en el desenvolupament de la Catalunya contemporània. Barcelona: Fundació Enciclopèdia Catalana, 2000.

Marcos MarTín, A. España en los siglos XVI, XVII y XVIII. Economía y sociedad. Barcelona: Crítica, 2000.

martín García, G. La industria textil en Ávila durante la etapa final de Antiguo Régimen: la Real Fábrica de Algodones. Diputación Provincial de Ávila, 1989.

martín Rodríguez, M. Historia del pensamiento económico en Andalucía. Granada: Comares, 2012.

MARTínez SHaw, C. "La Cataluña del siglo XVIII: bajo el signo de la expansión». En FernáNDEZ DíAz, R. (ed.). España en el siglo XVIII (Homenaje a P. Vilar). Barcelona: Crítica, 1985, pp. 55-131. 
JOAQUÍN OCAMPO SUÁREZ-VALDÉS Y PATRICIA SUÁREZ CANO

MARURI VillanUEVA, R. y MAISO GONZÁLEZ, J. «Iniciativas empresariales y modernización económica en la Cantabria del siglo XVIII». En OCAMPO, J. (ed.). Empresas y empresarios en el norte de España (siglo XVIII). Gijón: Trea, 2912, pp. 123-153.

MELÓN JimÉNEZ, M. A. «Un capítulo singular de la historia extremeña: la Real Compañía de Comercio y Fábricas de Extremadura (1746-1756)». Revista de Estudios Extremeños, 1987, vol. 43, 2, pp. 593-528.

Melón Jiménez, M. A. Extremadura en el Antiguo Régimen. Mérida, 1989.

Moll Blanes, I. "La política agraria de la Sociedad Mallorquina de Amigos del País (17781803)». Boletín de la Cámara Oficial de Comercio, Industria y Navegación. Palma de Mallorca, 1973.

Moll Blanes, I. y SuAu Puig, J. «Memoria explicativa del estado de las islas de Mallorca en el siglo XVIII». En FERNÁNDEZ Díaz, R. (ed.). España en el siglo XVIII (Homenaje a P. Vilar). Barcelona: Crítica, 1985, pp. 249-288.

MORENO FERNÁNDEZ, J. R. "Serranos hacedores de paños: pluriactividad y protoindustria en la Montaña riojana (c. 1750)». Revista de Historia Industrial, 2004, 25, pp. 11-46.

MORENO LÁzARO, J. "Los inicios de la producción fabril de harina en España (1770-1800)». Revista de Historia Industrial, 1992, 2, pp. 181-187.

NADAL, J. «Cataluña, la fábrica de España». En NADAL, J. Moler, tejer, fundir. Estudios de historia industrial. Barcelona: Ariel, 1992.

Nieto, J. A. y Zofio, J. C. "Los gremios de Madrid durante la Edad Moderna: una revisión». Áreas. Revista Internacional de Ciencias Sociales, 2015, 35, pp. 47-61.

Nieto-Galán, A. La seducción de las máquinas: vapores, submarinos, inventores. Madrid: Nívola, 2000.

Nieto-Galán, A. y Roca Rosell, A. (coords.). La Reial Acadèmia de Ciències i Arts de Barcelona als segles XVIII $i$ XIX. Història, ciencia $i$ societat. Barcelona: Institut d'Estudis Catalans, 2000.

OCAMPO, J. «Empresas y empresarios en el siglo XVIII». En OCAMPO, J. (ed.). Empresas y empresarios en el norte de España (siglo XVIII). Gijón: Trea, 2012, pp. 9-38.

OCAMPO, J. «Industrialismo antes de la revolución industrial: la visión de los ilustrados». Cuadernos de Estudios del Siglo XVIII, 2002, 12-13, pp. 93-115.

OCAMPO, J. "Los catalanes en España y la Economía política de la Ilustración: ¿"Conquista pacífica" o "Españas vencidas"?». Revista de Historia Moderna, 2010, 29, pp. 185-203.

OCAMPO, J. "Economía, Ilustración y Liberalismo: las Cortes de Cádiz». Brocar, 2012, 36, pp. 139-161.

PERDICES DE BLAS, L. «La restauración de la riqueza de España por la industria. Reflexiones sobre el industrialismo de los arbitristas del siglo XVII». En BEL, G. (coord.). Industrialización en España: entusiasmos, desencantos y rechazos. Madrid: Cívitas, 1997, pp. 31-61.

Pérez González, P. y Domínguez MarTín, R. «El desarrollo económico de Cantabria en perspectiva histórica». Papeles de Economía Española, 1990, 13, pp. 28-44.

Pérez PicAzo, M. T. y Lemeunier. G. El proceso de modernización de la región murciana, siglos XVI-XIX. Murcia: Ed. Regional, 1984.

Riera i TuÈBols, S. Ciència i tècnica a la Ilustració: Francesc Salvá i Campillo (1751-1828). Barcelona, 1985.

Ringrose, D. R. Madrid y la economía española, 1560-1850. Ciudad, Corte y País en el Antiguo Régimen. Madrid: Alianza 1985. 
Ruiz TORRES, P. «El País Valenciano en el siglo XVIII: la transformación de una sociedad agraria en la época del absolutismo». En Fernández DíAz, R. (ed.). España en el siglo XVIII (Homenaje a P. Vilar). Barcelona: Crítica, 1985, pp. 132-248.

SáncheZ Hormigo, A. (ed.). J. Polo y Catalina: Informe sobre las fábricas e industria de España (1804) y otros escritos. Ed. y estudio preliminar. Zaragoza: Prensas Universitarias, 2005.

SANTOS ISERN, Vicente M. Cara y cruz de la sedería valenciana (siglos XVIII-XIX). Valencia: Institución Alfonso El Magnánimo, 1981.

SARASÚA, C. «Innovaciones técnicas para abaratar los costes del trabajo en la España preindustrial. El programa ilustrado para la industria sedera». En COMín, F.; HERNÁNDEZ, R. y MORENO, J. (eds.). Instituciones politicas, comportamientos sociales y atraso económico en Espana, 1500-2000. Salamanca: Ediciones de la Universidad de Salamanca, 2017, pp. 189-210.

SILVÁn, L. Los estudios científicos en Vergara a fines del siglo XVIII. San Sebastián, 1953.

TedDE, P. «La empresa pública en el mercantilismo español del siglo XVIII». En Comín, F. y Martín ACEÑa, P. (dirs.). Historia de la empresa pública en España. Madrid: EspasaCalpe, pp. 25-50.

Thompson, J. El orígens de la industrialització a Catalunya. El cotó a Barcelona, 17281832. Barcelona: Ed. 62, 1994.

Tinoco Rubiales, S. "Capital y crédito en la Baja Andalucía». En Fontana, J. (ed.). La economía española al final del Antiguo Régimen. Comercio y colonias. Madrid: Banco de España, 1982, pp. 299-331.

TORRAS, J. «La economía aragonesa en la transición al capitalismo. Un ensayo». En TORRAS, J.; ForCADEll, C. y FERNÁNDEZ, E. (eds.). Tres estudios de historia económica de Aragón. Zaragoza, 1982, pp. 123-176.

URIARTE AYO, R. Estructura, desarrollo y crisis de la siderurgia tradicional vizcaína (17001840). Universidad del País Vasco, 1988.

Urteaga, M. (ed.). El Tratado de Metalurgia de las Comisiones (Segundas) de la Real Sociedad Bascongada de los Amigos del País (1765-1773). San Sebastián: Diputación Foral, 2000.

Vallés Garrido, J. M. (ed.). La Real Sociedad Segoviana de Amigos del País en el siglo XVIII. En Los Estatutos de la Real Sociedad de Amigos del País de la ciudad de Segovia (1781). Segovia, 1996.

Velázquez GonZÁlez, M. «Las primeras gestiones de la Real Sociedad Económica de Murcia en aras de la regeneración económica del Reino". Contrastes. Revista de Historia Moderna, 1986, vol. 2, pp. 141-156.

Viguera Ruiz, R. «La Real Sociedad Económica de la Rioja Castellana y su apuesta por el progreso". Berceo, 2003, 152, pp. 79-122.

VIlar, P. "La Cataluña industrial». En VIlar, P. et. al. (eds.). La industrialización europea. Estadios y tipos. Barcelona: Crítica, 1981.

Villar García, M. B. y Pezzi, P. (eds.). Los extranjeros en la España moderna. Málaga, 2003.

Villas Tinoco, S. "Málaga, el mundo del trabajo u la Sociedad Económica de Amigos del País en el siglo XVIII. Jabega, 1982, 43, pp. 34-43.

Yun CaSAlilla, B. «Mercado de cereal y burguesía en Castilla, 1750-1868 (Sobre el papel de la agricultura en el crecimiento económico regional)». En Yun Casalilla, B. (coord.). Estudios sobre capitalismo agrario, crédito e industria en Castilla (siglos XIX y XX). Salamanca: Junta de Castilla y León, 1991, pp. 47-76.

Zorraquino, J. I. «Las colonias mercantiles extranjeras en Aragón». En Villar García, M. B. y Pezzi, P. (eds.). Los extranjeros en la España moderna. Málaga, 2003, I, pp. 27-45. 